\title{
Improving Special Education Teacher Quality and Effectiveness
}

\author{
BONNIE BILLINGSLEY \\ Virginia Tech \\ ELIZABETH BETTINI \\ Boston University
}

Over time, teachers matter more to student achievement than any other school based factor (Chetty, Friedman, \& Rockoff, 2011; Rivkin, Hanushek \& Kain, 2005). The relationship between teacher and student achievement has been well documented in general education, and some limited research indicates that special education teachers (SETs) play an important role in promoting achievement gains for students with disabilities (Feng \& Sass, 2013). The national policy conversation around teaching focuses primarily on teacher effectiveness, meaning specifically teachers' effects on students' outcomes. Teachers are "differentially effective" (Goe, Bell, \& Little, 2008, p. 47), with some teachers promoting stronger gains than others, as well as promoting stronger gains in some contexts than others. Understanding the range of factors that influence SET quality and effectiveness is necessary so that strategic efforts can be taken to improve students with disabilities' access to SETs who can support their growth in academic, behavioral, social-emotional, and functional domains. The purpose of this chapter is to provide a broad perspective of factors that show evidence of influencing the effectiveness of the SET workforce. Consideration is given to critical issues, research needs, and implications for policy-makers and leaders.

Much of the research about SET quality and effectiveness has been funded through the U.S. Department of Education's Office of Special Education Programs (OSEP) and Institute for Education Sciences (IES) over the last 20 years. These initiatives include supply and demand studies led by Erling Boe (e.g., Boe, 2006; Boe, Cook \& Sunderland, 2007b), using data from the Schools and Staffing Surveys (SASS), and the Study of Personnel Needs in Special Education (SPeNSE), under the direction of Elaine Carlson at WESTAT, which assessed factors influencing the availability and development of a qualified SET workforce. (Carlson, Lee \& Scroll,
2004). Federal funding priorities targeting the topic of "Professional Development (PD) for Teachers and Related Service Providers" have contributed new knowledge about PD practices that promote SETs' learning. OSEP funded technical assistance centers have synthesized research and provided intensive assistance to stakeholders to translate this research into policy and practice. Significant contributions to the knowledge base supporting special education teacher quality can be credited to the work of the Center for Personnel Studies in Special Education (COPSSE), the National Center to Inform Policy and Practice in Special Education Professional Development (NCIPP) and the Center for Collaboration for Effective Educator Development, Accountability, and Reform (CEEDAR) directed by Mary Brownell, Paul Sindelar, and Erica McCray at the University of Florida. In addition, under OSEP's 325T grant competition, 72 institutions of higher education were supported in reforming their SET preparation programs to better prepare educators to implement evidence-based practices for students with high-incidence disabilities.

\section{Conceptualizing Special Education Teacher Quality and Effectiveness}

Defining and studying teacher quality and effectiveness in special education is complex and challenging, particularly because there is a lack of agreement on what these terms mean. In this section, we provide a brief overview of different ways SET quality and effectiveness have been conceptualized, and how these different conceptualizations have been operationalized in research on factors influencing special education teacher quality and effectiveness.

Traditionally, educational policy has defined SET quality in terms of quantifiable inputs (i.e., teacher qualifications) 
that are believed to contribute to teachers' capacity to implement effective practices and promote positive student outcomes. These inputs include preparation experiences, professional development hours, experience teaching, and certification status. This conception forms the basis for policies requiring teachers to obtain certification to teach. Researchers using this conception of SET quality have compared the qualifications of teachers of students with behavioral disorders and other SETs (Billingsley, Fall \& Williams, 2006) and compared the qualifications of SETs working in high- and low-poverty schools (e.g., Fall \& Billingsley, 2008; Mason-Williams, 2015)).

A second way to conceptualize SET quality is behavioral, with a focus on what teachers actually do and whether their actions align with practices known to be effective in promoting positive student outcomes (Brownell, Steinbrecher et al., 2014). This conception of teacher quality is also sometimes termed teaching quality (Hiebert \& Morris, 2012) or instructional quality (Brownell, Steinbrecher et al., 2014). Because teachers influence student learning through how they choose to teach, effective SETs are those who use research-based instructional practices, such as modeling, eliciting student responses, and so on. This conceptualization is embedded in studies that observe and analyze teachers' instruction (e.g., Jones \& Brownell, 2014; Nougaret, Scruggs, \& Mastropieri, 2005).

A third approach in conceptualizing SET quality is to consider what effects we expect quality teachers to achieve. Often termed teacher effectiveness, this conceptualization aligns with the idea that a quality teacher is one who is effective in achieving desired outcomes. This conceptualization is predominant in recent U.S. policy initiatives, such as Race to the Top (RtT) and Every Student Succeeds Act (ESSA), and in the use of value added modeling (VAM) to evaluate teachers. Yet, this conceptualization of teacher quality raises the question of what specific outcomes should be valued: SETs' contribution to student gains on standardized tests, to their social emotional skills, to student attendance and engagement, or to longer-term outcomes such as employment? These questions are particularly contentious in special education, which has long grappled with tension between promoting students' individualized learning goals and ensuring that students have equitable access to and achievement in general education curricular standards (McLaughlin, 2010). The question of SET effectiveness is also controversial, as SETs may have limited influence over other factors that influence learning, such as student attendance, caseload, and time for instruction. Although a large body of research in general education has examined teachers' contributions to student achievement gains, there is limited research of this nature with SETs, likely because of substantial complexities involved in calculating and interpreting VAM scores for SETs (Jones, Buzick, \& Turkan, 2013). Instead, studies typically quantify SETs' effects on student outcomes in terms of student growth on curriculum-based measures (e.g. oral reading fluency probes; Brownell et al., 2016).

These three conceptualizations are not independent; Brownell, Steinbrecher, and colleagues (2014) illustrated how these outcomes may interact. Their model posits that student outcomes (teacher effectiveness) are a function of teachers' classroom practices (teaching quality), which are in turn a function of knowledge gained through preparation and experience (e.g. teacher qualifications), as well as their own dispositions, access to instructional resources, time constraints, collaborative opportunities, and interactions between student needs and content demands. Researchers have also examined relationships among qualifications, teaching quality, and student outcomes. For instance, Feng and Sass (2013) used Florida's state data set to examine how teacher qualifications (experience, preparation) predicted teacher effectiveness (i.e., students with disabilities' achievement gains in reading and math); they found that SETs with stronger preparation and more experience were more effective in promoting students with disabilities' achievement gains. Similarly, Brownell and colleagues (2009) examined how beginning SETs' knowledge of effective reading practices related to their instructional practices (teaching quality) and their students reading achievement gains (teacher effectiveness). They found that knowledge was unrelated to practice, but practice did predict students' achievement gains.

\section{Factors Influencing SET Quality and Effectiveness}

Research using different conceptualizations of SET quality has provided important insights into a variety of factors influencing teacher quality and effectiveness. As shown in Figure 33.1, these factors fall within three major domains: (a) supply and demand, (b) professional knowledge and skills, and (c) conditions of service (Carlson \& Billingsley, 2010). These interrelated factors have an impact on teachers' qualifications and the extent to which they are effective in their work.

\section{The Shortage: Special Education Teacher Demand, Supply, and Retention}

Over the last decades demand for SETs consistently increased, and as more students were identified with disabilities, more SETs were needed to serve them (Boe, 2006). Throughout this period, the supply of qualified SETs consistently lagged behind demand, creating persistent shortages of qualified personnel (Boe, 2006; McLeskey \& Billingsley, 2008; McLeskey, Tyler, \& Flippin, 2004). Traditional economic models suggest shortages exist when demand exceeds supply. Teacher shortages have typically been conceptualized in two ways. Conceptualizing 


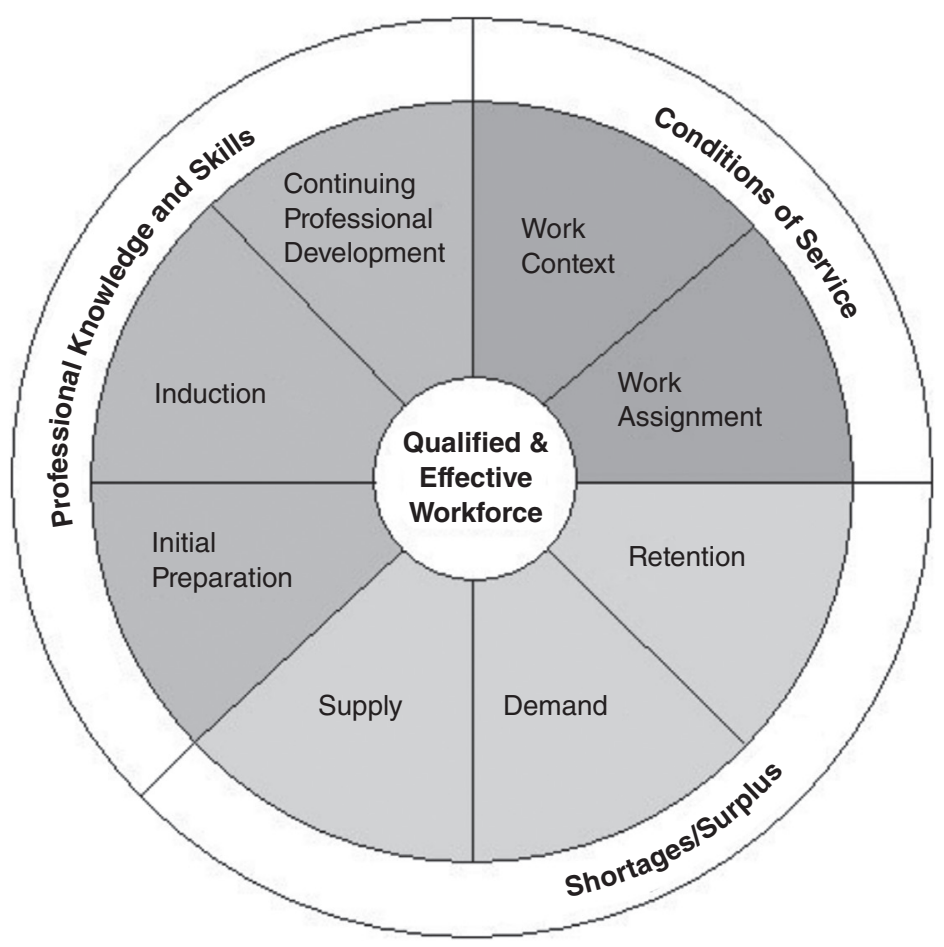

Figure 33.1 Factors Influencing Teacher Quality and Effectiveness.

Source: Carlson \& Billingsley, 2010, revised.

the shortage as a "quantity problem," some scholars have examined the proportion of vacancies that are not filled by any teacher (e.g. McLeskey et al., 2004). Other scholars have conceptualized the shortage as a "quality problem," examining the proportion of teachers hired who are uncertified or unprepared for special education teaching (e.g. Fall \& Billingsley, 2008; Mason-Williams, 2015). In the following sections, we first describe current research on the overall supply and demand for SETs and then discuss research examining supply and demand of SETs for schools serving historically marginalized students (e.g. students living in poverty, students of color) and supply and demand of SETs from historically marginalized populations. We conclude by discussing how retention contributes to supply and demand.

\section{Current Supply and Demand}

To secure a qualified workforce, it is necessary to have an adequate supply of teachers who are able and willing to teach. Supply is conceptualized as "the number of qualified individuals willing to teach at a given level of overall compensation" (Guarino, Santibañez, \& Daley, 2006, p. 174). In contrast, McLeskey et al. (2004) take a "quantity" perspective defining teacher supply as including both qualified and unqualified SETs. The latter definition is consistent with the fact that many SETs hired over the last decades have not been fully certified for their positions.

Although shortages persist, Boe et al. (2013) reported a decline in demand for the first time in the history of the field of special education, reporting that U.S. schools employed 13\% fewer SETs in 2009 than in 2006. Dewey and colleagues (in press) found these declines continued through 2012 when U.S. schools employed 17\% fewer SETs than in 2006. Dewey and colleagues considered several factors contributing to the decrease with the greatest being the declining prevalence of students with disabilities, declines in the investment in special education teachers relative to general education teachers, and reduced investment in educational resources concurrent with the recession. Although demand lessened during this period, it also appears that supply may be declining. Forty-nine state education agencies (SEAs), including every state except for Oklahoma, continued to report shortages of SETs (National Coalition on Personnel Shortages in Special Education and Related Services, n.d.). Another problematic trend concerns enrollments in teacher preparation programs, which are lower than at any point since the National Center for Education Statistics (NCES) began collecting statistics on enrollment in teacher preparation, suggesting that overall the supply of teachers, in general, is declining.

Massachusetts recently commissioned more detailed projections of its supply and demand for educators (Levin, Berg-Jacobsen, Atchinson, Lee, \& Vontsolos, 2015). Levin and colleagues found demand for SETs is declining and is projected to continue declining by almost $14 \%$ over the next decade, due in part to declining student enrollment and declining prevalence of disabilities. Yet, the projected 
supply is expected to decline even faster, by $20-26 \%$, over the same period. Overall, the current SET shortage of $3 \%$ is projected to grow to almost $8 \%$ in the next 10 years. Consistent with historical trends (Berry, Petrin, Gravelle, \& Farmer, 2012; Tyler, Yzquierdo, Lopez-Reyna, \& Flippin, 2004), the projected shortage is greatest in high-poverty urban districts and rural areas (Levin et al., 2015).

\section{Shortages in Hard-to-Staff Schools and Districts}

A limitation of national data is that it does not account for the distribution of teachers across different types of districts, especially rural and high poverty districts, which have serious shortages. High-poverty schools and districts are disproportionately staffed by less qualified GETs (Boyd, Grossman, Lankford, Loeb, \& Wyckoff, 2008; Kalogrides, Loeb, \& Beteille, 2013) and SETs (Fall \& Billingsley, 2008; Mason-Williams, 2015). Analyzing data from SPeNSE, Fall and Billingsley (2008) reported SETs in high-poverty districts were less prepared on a range of quality indicators, including certification, possession of advanced degrees, graduation from selective institutions, performance on teacher tests, and extent of time spent student teaching. They also reported $29.7 \%$ of early career SETs in high-poverty districts lacked full certification compared to $14 \%$ of their counterparts in more affluent districts. Even more troubling, 24\% of early career SETs in high-poverty districts held emergency certificates compared to only $2 \%$ in more affluent districts. Mason-Williams (2015) obtained similar results. Analyzing SASS:04 data, she compared SETs' qualifications in low-poverty schools to SETs' qualifications in high-poverty schools. SETs in high-poverty schools were significantly less likely to be fully prepared, to have a degree in teaching, to be certified, to have received their preparation through a traditional teacher preparation program, and to have more than 3 years of experience (Mason-Williams, 2015).

Rural schools also struggle with recruitment and retention of qualified SETs (Berry et al., 2012). Berry and colleagues conducted surveys with 377 administrators and 203 SETs serving in a random national sample of rural schools and districts. More than half of the administrators reported "moderate or extreme difficulties" (p. 6) filling SETs' positions, especially for teaching students with behavioral challenges (e.g., emotional disturbance, autism) and low-incidence disabilities (e.g., multiple disabilities, sensory impairments). Some $72 \%$ of administrators reported retention was a major problem, and $42 \%$ of SETs reported planning to leave their positions in the next 5 years. Of those planning to leave, $25 \%$ planned to move into other teaching positions (i.e. general education, different schools, etc.), $27 \%$ cited retirement as their reason for leaving, and $25 \%$ cited burnout or stress as their reason for leaving.

Mason-Williams and Gagnon (2016) suggest the shortage may also disproportionately affect staffing in dedicated special education schools. Analyzing data from the
SASS:08, Mason-Williams and Gagnon found secondary SETs serving in special education schools are less likely to hold content area certification than secondary SETs in neighborhood schools.

\section{Shortage of SETs from Diverse Backgrounds}

The cultural, ethnic, and racial diversity of the U.S. student population is not represented in the SET workforce (Tyler et al., 2004). In a systematic review, Tyler and colleagues emphasized that, while roughly a third of individuals in the US at the time were from historically underrepresented groups, only $14 \%$ of early career SETs were from such groups. The diversity of the SET workforce does not match the diversity of its students. However, high-poverty districts have a higher proportion of teachers who share their backgrounds (Fall \& Billingsley, 2008).

A diverse SET workforce is hypothesized to be important for all students' outcomes, but especially for students with disabilities from historically marginalized groups. A cultural mismatch between predominantly White teachers and students of color has been implicated in the disproportionate over- and under-representation of students of color in certain disability categories (Skiba et al., 2008). Increasing the diversity of the SET workforce is hypothesized to be important for reducing cultural mismatches, and there is emerging research suggesting that students benefit from having at least some teachers who share their cultural, ethnic, and linguistic backgrounds (Achinstein, Ogawa, Sexton, \& Frietas, 2010). Teachers who share students' backgrounds may be less susceptible to deficit perspectives on diverse students' cultural norms, and they more easily create linkages between academic content and students' prior knowledge (Achinstein et al., 2010). Alternative route (AR) programs have been somewhat more successful than traditional preparation programs in recruiting diverse students (Rosenberg \& Sindelar, 2005). However, few studies have explored factors that contribute to recruitment and retention of culturally and linguistically diverse special education teacher candidates (López-Estrada \& Koyama, 2010).

\section{Retention}

Teacher retention contributes to supply and demand, because a stable workforce reduces the demand for new teachers. Differing estimates of the rates of retention and attrition are largely the result of varied definitions of leaving a position. Boe, Cook, and Sunderland (2007b) characterize teacher turnover in three ways: (1) leaving for non-teaching activities (attrition), (2) transferring from special education to general education teaching (transfers), or (3) moving to other special education positions (migration). When all three types of turnover were considered, rates increased from $18.8 \%$ in $1991-1992$ to $28.7 \%$ in 2004-2005 (Boe et al., 2007b). This means that more than 1 in 4 special education teachers did not return to the same position from one year to the next in 2004-20005. Boe and colleagues (2007b) reported no significant differences 
between GETs and SETs in rates of attrition and transfer, although migration was significantly higher among SETs. Analyzing the SASS, a nationally representative survey, Boe et al. (2007b) demonstrated that attrition rates rose through the early $2000 \mathrm{~s}$, with $5.2 \%$ of SETs leaving teaching employment in 1991-1992, 6.6\% leaving in 1994-1995, 8.7\% leaving in 2000-2001, and 10\% leaving teaching in 2004-2005.

The transfer from special to general education teaching has been studied less frequently than attrition or migration. Boe and colleagues (2008a) reported that $5.5 \%$ of SETs transferred to general education teaching in 1991-1992, $8.8 \%$ in 1994-1995 and 10.2\% in 2000-2001. These SETs are still serving students, and they are likely serving students with disabilities in general education settings - but they nevertheless represent a loss to the special education teaching workforce. Most of the data Boe and colleagues (2006; 2007b; 2008a) analyzed is more than a decade old, and more current research is needed to determine whether the trends identified by those studies still hold.

New teachers and SETs are both at risk of leaving their positions. Smith and Ingersoll (2004) found that, among first year teachers, SETs leave at 2.5 times the rate of general educators. In part, this may be attributable to the fact that a larger proportion of beginning SETs are only partly certified (44.4\%) (Boe \& Cook, 2006, p. 450) and uncertified teachers are at greater risk for leaving than their certified peers (Miller, Brownell, \& Smith, 1999).

Although some turnover (i.e., of less effective teachers, retiring teachers, teachers entering administrative roles, etc.) is healthy and necessary, high levels of turnover carry substantial financial and academic costs. No studies have specifically examined the costs of special education teacher attrition, but studies of general educators have documented that when teachers leave, there are financial consequences for districts and academic consequences for students. Financially, the money invested in training, hiring, and inducting teachers is lost when they leave (Milanowski \& Odden, 2007). In addition, teacher attrition is costly in terms of student achievement (Ronfeldt, Loeb, \& Wyckoff, 2013). In an analysis of New York City Public Schools data, Ronfeldt and colleagues found that students in grades with higher teacher turnover made smaller academic gains than students from the same school in different grades with lower turnover. In addition, they made smaller gains than students who attended that grade and school in a year with lower turnover. This effect was accounted for by the fact that, on average, teachers who left were replaced by less effective teachers. In addition, teachers who stayed were less effective in years when their grade level had experienced more turnover. They termed this the "disruptive" effect of turnover; when one member of a team leaves, their expertise leaves with them, and the remaining teachers have to support someone new rather than being mutually supported by someone who is already experienced in their school and grade level (Ronfeldt et al., 2013).
It is likely that similar mechanisms would be at play among SETs, but no studies have empirically examined the academic and financial consequences of special education teacher attrition. In particular, the disruptive effect may be especially salient for special education teachers. Because SETs often work in interdisciplinary collaborative teams across multiple grade levels, their turnover may interfere with established collaborative and co-teaching relationships that support students with disabilities throughout the school (McLeskey \& Billingsley, 2008). Consistent with this possibility, Sindelar, Shearer, Yendol-Hoppey, and Liebert (2006) reported that, when key individuals in an inclusive effort left the school, new teachers who replaced them were not as committed to or as knowledgeable about implementing inclusive instruction. As such, attrition of experienced SETs was a factor that contributed to the decline of the inclusive program.

Research does not currently provide insights into the effectiveness of SETs who leave compared to those who stay. Boyd and colleagues (2008) have explored this issue with regard to general education teachers. Analyzing New York City data, they found that first year teachers who were least effective were also most likely to leave. This may be interpreted positively, as appropriate attrition among teachers least capable of effectively serving students; however, it is not clear whether ineffective first year teachers left because they lacked capacity to be effective, or whether ineffectiveness might have been caused by other factors (e.g. unsupportive working conditions, lack of qualifications) that also contribute to decisions to leave teaching. Boyd et al. also examined patterns of attrition among second and third year teachers and reported the most effective teachers transferred disproportionately to higher performing schools serving fewer students of color. Boyd et al. concluded that patterns of new teacher attrition likely contribute to racial and socio-economic disparities in students' access to skilled teachers. However, no scholarship to date has examined whether SET attrition and migration follow the same patterns.

\section{Summary and Discussion}

Despite changes in demand, the SET shortage continues to be a substantial concern. The Labor Market Theory of Supply and Demand provides a helpful lens for policymakers and administrators interested in improving teacher recruitment and retention (Guarino et al. 2006). This theory suggests that individuals will enter into teaching and remain if it is the most attractive activity available based on overall compensation. In this case compensation includes all valued aspects of the job to the individual including salary and benefits, desirability of work conditions, opportunities for continued learning, and ancillary factors, such as school location, the schedule of work, and proximity to home. As Guarino and colleagues explained, conditions of work include any aspect of the job that influences teachers' desire to enter, stay or leave. Therefore elements 
of attractiveness are levers that school, district, and state leaders can use to recruit and retain teachers.

Possible avenues for increasing the attractiveness of the profession include: (a) recruiting young people by developing their interest in teaching, for instance, through pipeline programs (e.g. Brooks, Kaimal, Savage, \& Gonzaga, 2012); (b) preparing pre-service teachers with the skills to effectively serve students; (c) providing financial incentives for teaching in hard to staff positions, and especially for recruiting teachers from fields that have a surplus of teachers (e.g. elementary teacher) to special education; (d) preparing teachers from the geographic area, sometimes referred to as grow your own programs; and (e) retaining teachers over the course of their careers by providing supportive working conditions. Given the difficulties in recruiting teachers into special education, multiple strategies may be needed, particularly in attracting teachers to rural and high-poverty schools.

\section{Professional Knowledge and Skills}

Knowledgeable, skilled general and special educators are crucial for helping students with disabilities achieve high standards and meet individualized goals. In particular, SETs require strong preparation to navigate complex roles. They are often expected to teach a range of content areas effectively, use evidence-based instructional practices, monitor student performance, and respond to the needs of an increasingly diverse student population. SETs also need specific knowledge and skills to address challenging student behavior, help students meet transitionrelated goals, and teach non-academic goals such as social and self-advocacy skills.

SETs' professional knowledge and skills develop over the span of their entire career. A range of different experiences can promote SETs' knowledge and skills including initial teacher preparation, induction and mentoring, professional development, collegial interactions, and teacher evaluation experiences. In the following sections, we discuss evidence regarding how SETs' knowledge and skill develops through each of these different kinds of experiences and how these learning experiences influence their commitment and retention.

\section{Initial Preparation}

Initial preparation encompasses a very heterogeneous group of experiences, including undergraduate degrees in education, master's degrees, certification programs, and a wide range of alternative route programs. This heterogeneity has increased in the past 20 years, as traditional, university-based preparation programs have been the subject of extensive scrutiny and criticism; many have questioned the effectiveness and relevance of these programs (e.g. Walsh, 2001). These critiques, in combination with persistent shortages, led to policies allowing a wide range of alternative pathways into teaching, including Teach for America, Urban Residency Programs, and other Alternative Programs (Cochran-Smith \& Villegas, 2015). Consistent with trends in general education teacher preparation, fewer SETs are earning degrees in special education (Boe et al., 2007b) and more GETs and SETs are entering through alternative programs (Rosenberg \& Sindelar, 2005). Even within university programs, there is great diversity in program types, including programs preparing special and general educators separately, merged programs designed for all teachers, categorical programs and specializations, and cross-categorical programs (e.g., Leko, Brownell, Sindelar, \& Kiely, 2015; Pugach \& Blanton, 2009).

Effects of teacher preparation. Researchers use large databases to demonstrate that teacher preparation does make an important contribution to student outcomes. Studies have examined relationships among preparation (e.g., type of program, extent of preparation) and students' achievement gains. Many of these studies have obtained positive results, demonstrating that teacher preparation explains a small but significant proportion of the variance in teachers' effectiveness during their first 3 to 5 years teaching (Boyd, Grossman, Lankford, Loeb, \& Wyckoff, 2009; Clotfelter, Ladd, \& Vigdor, 2010; Jackson \& Brueggman, 2009; Ronfeldt, Schwartz, \& Jacob, 2014).

The majority of studies of the effects of teacher preparation have focused on mathematics and English language arts teachers, with only one large-scale study specifically investigating SETs. Using value-added modeling to examine Florida's state data, Feng and Sass (2013) found that initial preparation had substantial effects on SETs' ability to improve the achievement gains of students with disabilities, particularly in reading. More specifically, Feng and Sass reported that holding a bachelor's degree in special education, more hours of coursework, as well as teacher certification in special education were significantly related to the achievement gains of students with disabilities. Students taught by SETs who held an advanced degree also tended to have higher student achievement gains in math.

Two smaller studies considered the effects of preparation on SETs' knowledge and skills. Using the Danielson Framework for Teaching to evaluate teachers' instruction, Nougaret et al. (2005) compared two groups, first year teachers completing traditional certification and those on emergency certificates. Observers were blind to the preparation status of the teachers. Nougaret and colleagues reported that first year teachers completing traditional programs used more effective teaching practices and had better management skills than those with emergency certificates. In another study, Sindelar, Daunic and Rennells (2004) compared teachers who completed traditional and AR programs on observations of classroom performance. The AR teachers were comprised of two groups, those from university-district partnership programs and add-on district programs. They observed teachers using the Praxis III, using measures on planning to teach, 
classroom environment, instruction, and professionalism. Traditionally prepared SETs received higher ratings than the AR groups on instruction, but all teachers met a basic level of competence.

Further research is needed to evaluate the quality of graduates from AR programs, especially given the dramatic variation in these programs. Rosenberg, Boyer, Sindelar and Misra (2007) pointed out that about half of the 101 programs they studied required 3 months or less of training before SETs were hired as the teacher of record. In a review of AR programs, Rosenberg and Sindelar (2005) identified characteristics of stronger AR programs, including adequate program length with a variety of activities, meaningful coordination with IHEs, including IHE supervision, and school-based mentor support. In contrast, weaker programs were characterized by unanchored courses and activities that lacked a unified program approach.

Effects of specific teacher preparation practices. Studies described in the prior section sought to identify significant relationships between more extensive teacher preparation and outcomes of teaching quality, especially student achievement. By and large, these studies identified significant relationships (e.g. Feng \& Sass, 2013); yet, their focus on such a large, broadly defined independent variable (i.e. a teachers' amount or type of preparation) leaves many unanswered questions about what specific teacher preparation practices are most effective in promoting positive outcomes, and how teacher preparation programs might improve. In the past decade, a profusion of research on effective teacher preparation practices has sought to fill this gap, examining how specific preparation practices (e.g. video analysis) relate to teachers' knowledge, skill at implementing evidence based instructional practices, and student outcomes (Dieker, Kennedy, et al., 2014; Leko et al., 2015).

The set of special education teacher preparation practices that have the strongest evidence base are practicebased experiences that provide pre-service teachers with carefully sequenced, well-scaffolded opportunities to use evidence based instructional practices and obtain highquality feedback on their implementation of those practices (Leko et al., 2015). In a recent synthesis, Leko and colleagues identified practices that meet these criteria and that have some evidence to support their effectiveness in promoting pre-service teachers' expertise, including structured tutoring, coursework aligned with fieldwork, peer coaching, and technology-enhanced coaching. Structured tutoring is when pre-service teachers have opportunities to implement a specific practice in one-to-one instruction with a tutee, while receiving feedback from a skilled observer (e.g. Al Otaiba, 2005); structured tutoring has been shown to support changes in pre-service teachers' knowledge and practice, as well as their tutee's achievement (Leko et al., 2015). Coursework aligned field experiences provide pre-service teachers opportunities to implement content taught in coursework and receive feedback on their implementation of the content (e.g. Alexander Lignugaris-Kraft, \& Forbush, 2007); emerging evidence supports the idea that pre-service teachers whose coursework and field work are well-aligned may be better able to enact practices learned in coursework (Leko et al., 2015). Peer coaching is when pre-service teachers provide one another with performance feedback (e.g. Mallette et al., 1999) and limited evidence indicates that peer coaching can support pre-service teachers in becoming more reflective and improving their instruction (Leko et al., 2015). Technology-enhanced coaching (e.g. bug-inear) provides teachers with immediate positive and corrective feedback during their teaching, supporting changes in preservice teachers' practice (e.g. Rock et al., 2009).

Dieker, Kennedy, et al. (2014) reviewed research investigating the use of technology in preparing pre-service SETs. They identified three additional practices that have some evidence of promise, including content acquisition podcasts (CAPS), video case studies, and teaching simulations. Content acquisition podcasts (CAPs) are short, visually enhanced podcasts that provide pre-service teachers with introduction to key course content, in place of or in combination with text-based materials (e.g. journal article, book chapter). These studies demonstrate that pre-service teachers who view CAPs gain more knowledge than preservice teachers who only read text based materials (e.g., Kennedy, Hart, \& Kellems, 2011; Dieker, Kennedy et al., 2014), though scholars have not yet linked CAPs with pre-service teachers' use of the practices taught in the CAPs. Video case studies are videotaped stories of real situations, which provide pre-service teachers with opportunities to apply their knowledge to an authentic situation and, extant research indicates that video case studies can support pre-service teachers' knowledge development (e.g., Dieker et al., 2009; Dieker, Kennedy, et al. 2014). Teaching simulations, facilitated by TeachLive technology, allow pre-service teachers to practice instructional practices within virtual environments populated by avatars; very little research has been conducted on teaching simulations to date, but extant studies suggest that simulations hold promise for helping pre-service teachers learn to master instructional practices before implementing them with real students (e.g. Dieker, Hynes, Hughes, \& Straub, 2014; Dieker, Kennedy, et al., 2014).

\section{Induction}

New teachers often have "turbulent landings into their classrooms" (Kardos \& Johnson, 2010, p. 23) and even the best-prepared need systematic support aimed at continued teacher learning, improved teacher effectiveness, and teacher retention (Billingsley, Griffin, Smith, Kamman \& Israel, 2009; Ingersoll \& Strong, 2011). Research findings about new SETs' experiences clearly demonstrate that new SETs experience a range of challenges including (a) learning content, (b) learning to teach, (c) collaborating with classroom teachers and paraprofessionals 
while securing inclusive environments for their students, (d) managing student behavior, (e) scheduling, (f) finding instructional resources, (g) writing IEPs and dealing with special education processes, (h) managing their time and roles, (i) scheduling (Billingsley et al., 2009), and (j) teaching students from culturally and linguistically different backgrounds (Fall \& Billingsley, 2008). Although mentoring is often the primary induction activity, a range of supports and activities may be included such as systematic hiring practices, reduced responsibilities, meetings with other teachers, more frequent teacher evaluation (Ingersoll \& Strong, 2011; Smith \& Ingersoll, 2004) and curricular supports (Grossman \& Thompson, 2008).

Effects of induction and mentoring on retention. In a review of the empirical support for induction, Ingersoll and Strong (2011) emphasized that new teachers who participate in induction are more satisfied, committed and stayed longer than their less supported counterparts. Smith and Ingersoll (2004), in their study of over 3,000 first year teachers using SASS data, found teachers were half as likely to leave teaching or change schools when they participated in a comprehensive set of induction activities compared to those do did not participate in any. Supports associated with staying included having a mentor in the same field, common planning time with other teachers in the same subject area, regularly scheduled collaboration with other teachers, and participating in an external network of teachers. Investigations conducted following their study have also obtained similar results (e.g. DeAngelis, Wall, \& Che, 2013). Although only two studies investigated the relationship of induction and SETs' intent to stay, findings were mixed, possibly because differences in how plans to stay were articulated as short-term (Whitaker, 2000) versus longterm plans to stay (Billingsley, Carlson \& Klein, 2004).

The effects of induction and mentoring on attrition may be moderated by school poverty level; induction and mentoring significantly predicted teachers' career intentions and decisions in low-poverty schools, but this was not the case in studies conducted in high-poverty schools (Ingersoll \& Strong, 2011). Ingersoll and Strong suggest two possible explanations for this finding. First, induction programs in high-poverty schools may, on average, be of lower quality, and therefore have less effect on teachers' retention. Second, the conditions of teachers' work in high-poverty schools may be so difficult that induction and mentoring are insufficient to counter these trying conditions. No studies have examined whether or how school poverty may moderate the impact of induction on new SETs' retention, and more research is needed to examine whether this effect occurs among new SETs.

Effects of induction and mentoring on instructional quality and effectiveness. Teachers who participate in induction and mentoring report feeling more competent (Hunt, Powell, Little, \& Mike, 2013; Mathur, Gerhke, \& Kim, 2013), and there is some evidence that comprehensive induction can contribute to teacher effectiveness (Glazerman et al., 2010; Ingersoll \& Strong, 2011). Ingersoll and Strong's review found that, across studies, new teachers who participated in comprehensive induction used stronger instructional practices and were more effective in promoting student achievement. However, there are some substantial complexities to these effects. Glazerman and colleagues conducted a randomized controlled trial of induction that revealed some of these complexities. They randomly assigned 418 new teachers from 17 urban districts to either business-as-usual induction or a comprehensive induction that was based on the best evidence about the elements of effective induction (treatment). Some teachers received 1 year of treatment, while others received 2 years of treatment. They found that, among teachers who received only 1 year of induction support, treatment had no effect on teachers' practices or their students' achievement gains. Among teachers who received 2 years of comprehensive induction support, treatment had no effect on student achievement gains in the first 2 years, but it did have a lagged effect, significantly improving student achievement in year 3 . Their findings indicate that duration of induction matters for its effectiveness, and the effects of induction may take time to appear.

No studies comparable to Glazerman and colleagues' (2010) investigation have been conducted to examine the impact of induction on new SETs' instructional quality and effectiveness. However, several studies have documented that SETs who participate in more extensive induction do feel more competent. Billingsley and colleagues' (2004) study of over 1,000 early career SETs found that SETs receiving higher levels of formal mentoring reported greater job manageability and success in teaching difficult students than those with less support. Similarly, Boe, Cook, \& Sunderland (2008b) reported that induction was related to SETs' self-ratings of their preparedness to teach, pedagogical content knowledge, and ability to manage classrooms.

Components and design of induction programs. Some literature provides descriptions of induction and mentoring programs for special educators. In a literature review on induction in special education Billingsley et al. (2009) summarized that effective induction programs are situated within a culture of shared responsibility and support, are designed with clear goals in mind, and consider a range of ways to support new teachers, including mentoring, orientations, new teacher meetings, and professional development. Kamman and Long (2010) described a comprehensive induction program by the Special School District (SSD) of St. Louis County to increase teacher effectiveness and retention over a 5-year period. The induction program included a 2-day orientation, district and school-based mentors, and courses. Mentoring Academy I (which spans the first 3 years of teaching) supports greater levels of teacher effectiveness. Each SET is assigned a district-based instructional facilitator (full-time mentoring position) and a school-based 
mentor, each with different roles. The instructional facilitator provides 25 hours of mentoring a year, observing, looking for evidence of skills sets, and providing modeling, observations and coaching. All new SETs submit student data on a regular basis and mentors help mentees to use the data to monitor students' growth and inform instructional decisions. School-based mentors assist with immediate questions and policy and procedures for about 11 hours in the first year. Academy 2 is focused on improving SETs' use of research-based strategies and the continued use of student data to increase student achievement through teams of teachers, rather than mentors. Mentors and mentees document new SETs' progress in a portfolio that is assessed by a district supervisor. The SSD induction outcome data appear promising, showing increasing levels of teacher effectiveness and high levels of retention. Israel, Kamman, McCray and Sindelar (2014) demonstrated more specifically how evaluation activities tied to the district's instructional framework provided both mentors and mentees with a basis for feedback. They also questioned the assumption that mentoring and evaluation would need to be separated, as mentors' roles in evaluation did not adversely impact new SETs' mentoring experiences.

Induction may also be conceptualized more broadly, for example, attending to how teachers are selected and matched to positions as well as the broader conditions of work. Hiring and match is used to consider the extent to which teachers are placed in assignments that match their preparation and experience. Johnson, Kardos, Kauffman, Liu, and Donaldson (2004) explained the importance of match, stating that each job has a unique set of challenges and demands and a teacher's success depends not only on her overall qualifications, but also on the specific fit of the job to her skills and experiences. In special education, there is evidence that teacher-job match has a positive impact on commitment in a number of studies. In qualitative studies, teachers reported leaving because of varied problems with job match (e.g., students, service-delivery, school; Gehrke \& Murri, 2006). Given the range of SET certification areas, a $\mathrm{K}-12$ preparation focus, and varied service delivery models, it is likely that match is even more important and perhaps more difficult to achieve, in special than general education. The lack of match may explain why SETs migrate to other positions more often than other teachers (Boe et al., 2008a).

Less often studied is the role of working conditions that contribute to new teachers' instructional effectiveness. For example, several researchers have considered the role of instructional guidance through curriculum and materials. Youngs, Holdgreve-Resendez, and Qian (2011) demonstrated the helpfulness of a common language arts framework for teacher induction. They illustrated how a common instructional framework provided four new teachers with clear expectations about the curricular model used in the school, with latitude in instructional decision-making. These new teachers benefitted as principals, colleagues, and professional development experiences supported them in the use of the framework. Three teachers in other schools without the framework did not have the same quality induction experiences. Similarly, a series of studies by Grossman and Thompson (2004, 2008) demonstrated how curricular materials shaped new teachers' understanding of their content area and the pedagogical strategies they believed would support students' understanding of that content (Grossman \& Thompson, 2004, 2008).

Finally, SETs entering the work force through brief AR programs may need more extensive supports in their first years of teaching to be effective, adding to induction costs (unless provided by the AR program). Little is known about the extent to which LEAs differentiate to improve the knowledge and skills of minimally prepared SETs. Unfortunately, high-poverty schools have higher proportions of SETs with minimal qualifications than lower poverty schools (Fall \& Billingsley, 2008), leaving them with a disproportionate share of this burden.

Access to mentorship and induction. State education agencies (SEAs) are supporting the development of induction programs. Sindelar, Heretick, Hirsch, Rorrer and Dawson (2010) found that 48 SEAs addressed induction in policy, with at least 34 states providing some support for induction. However, Sindelar and colleagues suggest that districts continue to have discretion in the implementation of these programs. It is encouraging that SASS data suggests there is an increase in the proportion of GETs and SETs participating in induction, $81 \%$ and $80 \%$, respectively in 2011-2012 (SASS data) (Billingsley \& Williams, 2016). This represents an improvement over time, as in 2000 , only about $60 \%$ of SETs participated in induction (Boe, Cook, \& Sunderland, 2007a). However, $20 \%$ of teachers indicate they do not participate in mentor programs and inequities still exist across teacher groups. Billingsley and Williams (2016) reported that although a similar percentage of SETs in high- and low-poverty districts participated in induction programs, fewer SETs in high-poverty districts worked closely with a mentor and reported that mentoring resulted in improvement in their instruction. Wasburn-Moses (2010) also surveyed 232 new SETs and GETs, in two urban districts, finding that new GETS were more likely to have an assigned mentor (79.3\%) than GETs (64.4\%). In addition, SET mentors had less release time for mentoring and were less likely to be paid for mentoring, raising concerns about whether SETs' mentors would be as invested as those for GETs. Youngs and colleagues (2011) examined how two new SETs and two GETs made sense of their roles. New SETs' mentors were less able to provide their mentees with instructional guidance because they did not have the same instructional responsibilities as mentees, while GETs' mentors were often members of their grade-level team, with similar instructional responsibilities. 


\section{Professional Development}

After initial preparation, the development of teachers' knowledge and skills depends on professional development (PD), whether organized through educational agencies, ongoing coursework or SETs' own efforts to learn. Contemporary views of PD consider a broad range of contexts for learning, from formal programs to informal learning communities. Desmione (2009) considers the myriad of activities that contribute to teacher learning through co-teaching, analysis of student data, group discussions, self-analysis, and observations of others and in the selection and use of curriculum materials. Opportunities to learn are also growing in e-learning environments through e-mentoring and on-line communities of practice (Smith \& Ingersoll, 2004; Smith \& Israel, 2010).

The value-added study by Feng and Sass (2013) is the only large-scale study that investigated the relationship between SETs' participation in professional development (type and hours) and student achievement. They reported that PD had little effect on SETs' ability to promote achievement gains among students with disabilities. However, the database did not contain information about the quality or nature of the PD experiences, factors related to the effectiveness of these efforts.

Much of the work in professional development in special education has addressed the extent to which specific PD efforts result in changes in SETs' practices and the extent to which changes are sustained over time. Although there are many interventions shown to be effective with students with disabilities (e.g., Cook \& Schirmer, 2003), SETs do not necessarily use these practices (Englert \& Rozendahl, 2004), creating a research to practice gap. To address this need, systematic PD practices have been successful in facilitating teachers' use of classwide peer tutoring (Abbott, Greenwood, Buzhardt \& Tapia, 2006), peer-assisted learning strategies in mathematics (Baker, Gersten, Dimino \& Griffiths, 2004), effective literacy practices (Englert \& Rozendal, 2004), and collaborative strategic reading (Klingner, Arguelles, Hughes \& Vaughn, 2001) to name a few. Results of these research-to-practice studies have implications for the design of PD efforts. For example, Baker et al. found that factors influencing the long-term use of PALs in mathematics instruction included initial high-quality professional development and support that allowed teachers to reach a respectable level of mastery. Teachers also saw the social and cognitive benefits of peers working together, and had opportunities to see improvements in students' math outcomes. Other studies have also emphasized that teachers are more likely to use new practices when they receive support during implementation from colleagues and administrators and have evidence that it improves student learning (Abbott et al., 2006; Klingner, Ahwee, Pilonieta \& Menendez, 2003).

Although the emphasis of PD is to increase teacher expertise, improve instruction and ultimately improve student learning (Desmione, 2009), one study found that effective PD contributes to improved commitment to teaching. In a study of teacher attrition in three urban systems, Gersten, Keating, Yovanoff and Harniss (2001) using a path analysis model, found that PD had a direct effect on SETs' commitment to the profession and an indirect effect on teachers' intent to leave.

Learning through collegial interactions. A growing body of research indicates that formal and informal interactions with colleagues are an important source of professional learning for teachers, especially teachers who are just beginning their careers (Jackson \& Brueggman, 2009; Kraft \& Papay, 2014; Ronfeldt, Farmer, McQueen, \& Grissom, 2015; Sun, Loeb, \& Grissom, 2016). Analyzing data on fourth and fifth grade North Carolina teachers from 1995-2006, Jackson and Brueggman (2009) found that teachers' colleagues contributed significantly to variance in the value teachers added to their students' achievement gains; in particular, teachers' effectiveness was related to their colleagues' experience teaching and their colleagues' effectiveness at promoting student achievement gains. These effects were strongest for beginning teachers, suggesting colleagues may be contributing to beginning teachers' learning (Jackson \& Brueggman, 2009). More recently, Kraft and Papay (2014) analyzed data from a large North Carolina school district, examining whether variance in the degree to which new teachers improved could be explained by the characteristics of their schools and colleagues. They found that teachers working in schools with stronger professional cultures (characterized by collaboration, disciplinary support, trust, and mutual respect) improved their effectiveness more rapidly than teachers working in schools with weaker professional cultures; experience contributed more to teacher effectiveness when that experience was obtained in schools with climates that promoted positive, collaborative collegial interactions (Kraft \& Papay, 2014). Other recent studies have obtained similar results (Ronfeldt et al., 2015; Sun et al., 2016).

These studies provide promising evidence that teachers learn through collegial interactions, and schools that are structured to support meaningful collegial interactions may more effectively promote teacher quality and effectiveness (Jackson \& Brueggman, 2009; Kraft \& Papay, 2014; Ronfeldt et al., 2015; Sun et al., 2016). Yet none of these studies have included SETs. It is plausible that similar effects would occur for SETs; however, SETs report being significantly more isolated than general educators, and structuring schools to support their engagement with colleagues may be more challenging (Youngs et al., 2011). Further research is needed to understand how collegial interactions support SETs' learning, and how schools could be organized to maximize these learning opportunities.

Some professional development practices are designed to harness the potential of collegial learning, including professional learning communities (PLCs) and lesson study (LS). PLCs are designed to help create a culture and 
structure for professional growth within a school. PLCs are defined as "professionals in a school, typically groups of teachers, who work collaboratively to improve practice and enhance student learning" (Pugach, Blanton, Correa, McLeskey \& Langley, 2009, p. 6). In PLCs, teachers plan and work together to address instructional challenges, use student data to revise their teaching practices, and discuss what is working and what needs improvement. Professional learning communities and teacher leadership within these communities are designed with the view that expert teachers can facilitate effective instruction by participating in ongoing and school-embedded opportunities to learn (Mangin \& Stoelinga, 2008). PLCs have the potential to not only provide opportunities for SETs to learn with GETs, but may serve to reduce the isolation that some SETs experience (Pugach et al., 2009) and facilitate teacher leadership and retention (Billingsley, 2007).

Lesson study (LS) also relies on collegial interactions to promote teacher learning (Benedict, Park, Brownell, Lauterbach, \& Kiely, 2013). During the LS, teachers collaboratively plan lessons, observe and critique one another teaching those lessons, view products of students' work and use their observations to inform future lessons (Benedict et al., 2013; Benedict, 2014; Gersten, Dimino, Yayanthi, Kim, \& Santoro, 2010; Mutch-Jones, Puttnick, \& Minner, 2012). Studies have begun to explore how LS may be used to promote alignment of instruction across tiers within a multi-tiered system of support framework (Benedict, 2014), but more research is needed.

Learning through teacher evaluation. Given the influence of recent federal initiatives, (i.e., RttT), teacher evaluation has been one of the most prominent and controversial policies for improving the effectiveness of the education workforce (Brownell \& Jones, 2015). There are two mechanisms by which evaluation may contribute to teacher effectiveness (Sun, Mutcheson, \& Kim, 2015). First, teacher observation systems may contribute to their learning by providing them high-quality feedback about their instructional strengths and weaknesses (Sun et al., 2015; Taylor \& Tyler, 2012). Consistent with this possibility, Taylor and Tyler's quasi-experimental analysis of Cincinnati Public School data determined Cincinnati teachers were more effective during years in which they were evaluated by well-trained evaluators. No published research to date, however, has examined the effect of teacher evaluation on SETs' learning. Second, teacher evaluation may contribute to teacher quality and effectiveness by helping school leaders make high-stakes decisions intended to improve the composition of the teaching workforce-decisions about which teachers to dismiss, which need more professional development, and which should receive additional incentives (e.g. bonuses) and responsibilities (e.g. as mentors; Adnot, Dee, Katz, \& Wyckoff, 2016). Consistent with this possibility, Adnot and colleagues determined teachers who left Washington DC schools as a result of a low performance rating were replaced by teachers who were, on average, more effective at promoting students' achievement gains. Again, no published research to date has examined the effects of teacher evaluation on the composition of the special education workforce.

Special education teacher evaluation. There are many substantial concerns about how evaluation systems should be applied to SETs (Jones et al., 2013; Steinbrecher, Selig, Cosbey, \& Thorstensen, 2014). Typical teacher evaluation systems rely on a combination of observations and VAM scores. Recent scholarship (Jones et al., 2013; Steinbrecher et al., 2014) suggests that VAM scores have little utility for evaluating SETs for several reasons. First, they have floor effects that make them insensitive to the gains demonstrated by many students with disabilities; students with disabilities who make strong growth may not be able to demonstrate their growth on a standardized test, if their current skill level is below the "floor" measured by the test (Buzick \& Laitusis, 2010). Second, they are very sensitive to changes in the accommodations provided to these students. Students' scores vary widely depending on which accommodations (e.g., read-aloud, extra time, etc.) they use within a given year, and controlling for the effect of these accommodations would be necessary to ensure that students' measured growth (or lack thereof) is not due to a change in the accommodations they used. Third, estimates of the value a teacher adds are less stable when the scores of fewer than 10 students are used; this is problematic for SETs, who often serve small groups of students and thus are likely to have less stable scores (Buzick \& Laitusis, 2010). Finally, VAM scores rate each teacher individually, which ignores the shared variance that special and general educators, working collaboratively, contribute to the achievement gains of students with disabilities (Jones \& Brownell, 2014).

As such, scholars have recommended that the evaluation of special education teachers should rely primarily on observational evaluations of their instruction (Jones \& Brownell, 2014). Yet, this approach also poses challenges. Principals are often responsible for evaluating all teachers in their school, yet most principals seem to lack sufficient knowledge of SETs' work to accurately identify their instructional strengths and weaknesses, or to provide useful feedback (Steinbrecher, Fix, Mahal, Serna, \& McKeown, 2015). In addition, the most prominent observation instruments (e.g. Danielson's Framework for Teaching) were designed based on conceptions of good instruction that are not well matched with evidence-based special education instructional practices, such as explicit instruction (Jones \& Brownell, 2014). The validity of these instruments for measuring the effectiveness of instruction provided by SETs has not yet been examined.

Another concern is that SETs depend on collaborative interactions with GETs to contribute to the achievement of students with disabilities (Brownell, Sindelar, Kiely, \& Danielson, 2010; Scruggs, Mastropieri, \& McDuffie, 2007). 
Yet, current evaluation systems do not focus on helping teachers improve their collaborative efforts, nor have any studies examined how individual evaluation systems effect collaboration between special and general educators (Jones, Bettini, \& Brownell, 2016).

\section{Summary and Discussion}

There are many challenges to establishing linkages among SETs' professional learning experiences, their knowledge and skills, their instructional practices, and the outcomes of their students with disabilities. These challenges include the wide range of students served by SETs, varied service delivery models, the fact that an individual SET may work across several grades and content areas, validly measuring SETs' knowledge and practice, validly measuring students with disabilities' outcomes, accounting for collaborative efforts in the evaluation of SETs' effectiveness, the influence of school contexts on the ways SETs enact practices learned through professional learning experiences, and fact that initial teacher preparation is so distal from students' achievement outcomes (Jones et al., 2016; Leko et al., 2015).

Teacher preparation research findings have implications for educational leaders. To the extent possible, leaders should hire SETs with certification and degrees in special education. Given varied entry paths, educational leaders should assess the extent of prospective SETs' preparation (e.g., preparation length, extent of participation in methods courses and field work) and the extent to which a candidate's preparation and interests match a particular position. Leaders should also facilitate teachers' opportunities to collaborate with and learn from the most skilled teachers within a school (e.g. well-structured collaborative planning time, collaborative professional development) that support meaningful teacher interactions (Kraft \& Papay, 2014; Ronfeldt et al., 2013).

\section{Conditions of Service}

A compelling and growing body of research demonstrates that the conditions in which teachers work contribute to their instructional quality, effectiveness, and retention (Bettini, Crockett, Brownell, \& Merrill, 2016; Johnson et al., 2012; Ladd, 2009; Ronfeldt et al., 2015). Much of this research comes from large-scale studies of school effectiveness. For example, Johnson (2012) and colleagues reported that schools in which teachers rated their aggregated working conditions more highly were more effective at promoting student achievement gains and had higher levels of professional satisfaction. The working conditions that especially mattered were administrative support, collegial support, and community support. Analyzing data from North Carolina, Ladd (2009) obtained similar results; working conditions explained a significant proportion of the variance in schools' effectiveness at promoting students' achievement gains.
There are several mechanisms by which working conditions may contribute to the development of an SET workforce. First, an ample body of research indicates that working conditions contribute to SETs' intentions to continue teaching (Albrecht, Johns, Mountstevens, \& Olorunda, 2009; Bettini, Jones et al., forthcoming; Billingsley, 2004; Jones, Youngs, \& Frank, 2013). Second, working conditions can contribute to SETs' burnout, especially the emotional exhaustion component of burnout (Bettini, Jones et al., forthcoming; Brunsting, Srekovic, \& Lane, 2014); emotional exhaustion has been negatively associated with SETs' adherence to interventions for students with autism and their students' attainment of their individualized education program (IEP) goals (Ruble \& McGrew, 2013). Third, working conditions may facilitate opportunities for SETs to learn stronger pedagogical skills, for example, through interactions with colleagues (Jackson \& Brueggman, 2009; Kraft \& Papay, 2014; Ronfeldt et al., 2015), instructional resources (Grossman \& Thompson, 2004, 2008), and professional development (Yoon, Duncan, Lee, Scarloss, \& Shapley, 2007). Fourth, working conditions may influence SETs' opportunities to plan and deliver strong instruction (Bettini, Crockett et al., 2016). Finally, there is evidence that early career SETs in high-poverty schools have significantly less attractive working conditions than those in low poverty schools, a likely contributor to racial and socio-economic inequities in students' access to skilled special educators (Fall \& Billingsley, 2011)

Bettini, Crockett, and colleagues (2016) reviewed research investigating relationships among working conditions and SETs' instructional quality or the achievement of their students. They synthesized eight studies, along with a body of research on GETs, in a conceptual model (Figure 33.2) describing the working conditions that contribute to instructional quality and effectiveness. The working conditions identified in this review are briefly described below, including school culture, administrative support, collegial support, material resources, instructional grouping, instructional time, and planning time (professional development as a supportive condition was discussed previously).

\section{School Culture}

An extensive body of school effectiveness research has established the importance of school culture for student achievement (e.g. Goddard, Goddard, Kim, \& Miller, 2015; Hoy, Tarter, \& Hoy, 2006; Ronfeldt et al., 2015). A school's culture is defined by shared norms, values, and assumptions about how members of the school community should act and interact with each other, including assumptions about students and pedagogy (Hoy et al., 2006). School effectiveness studies have determined that, in schools with cultures characterized by collective efficacy, collaboration, academic press, faculty trust in schools and parents, and faculty trust in one another, teachers promote 


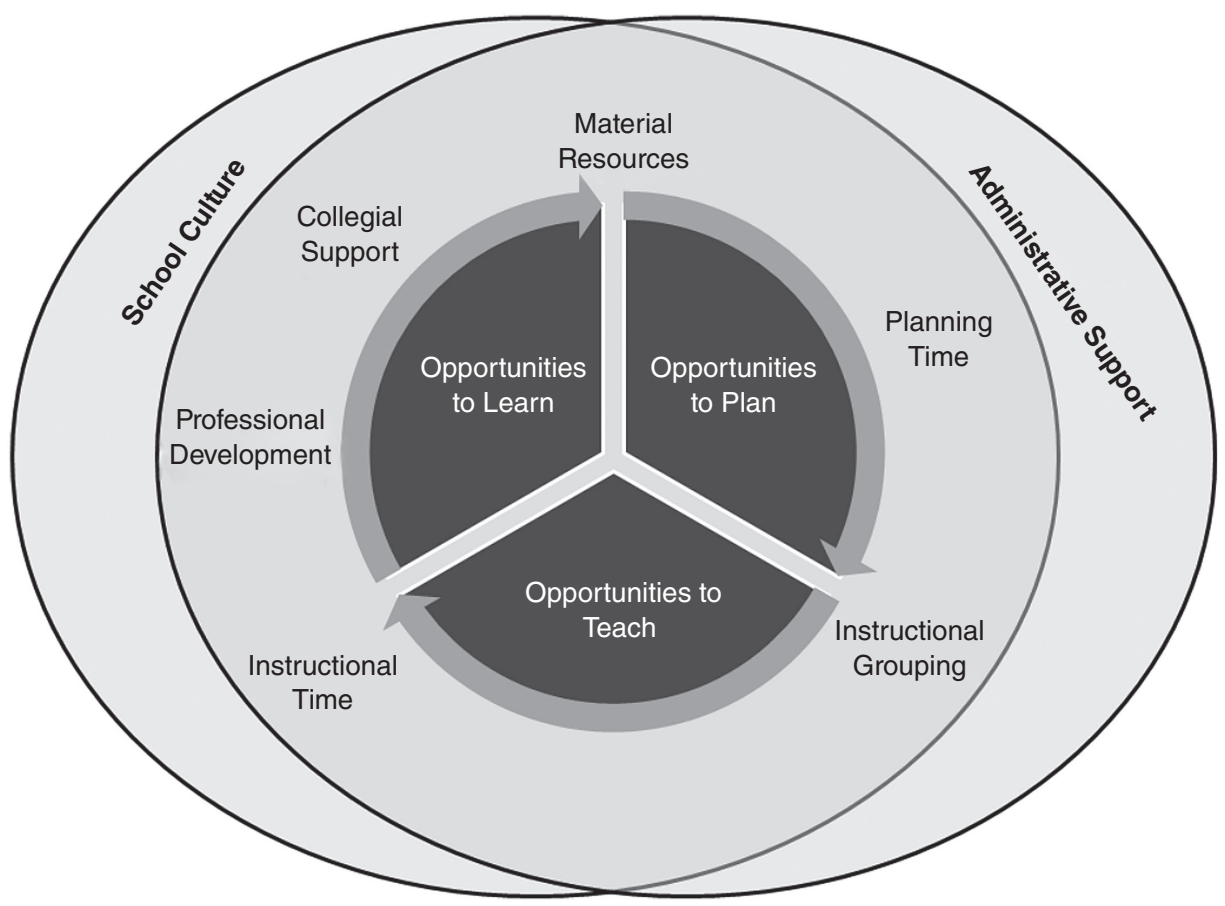

Figure 33.2 Conceptual Framework for How Working Conditions May Influence Special Educators' Instructional Quality.

Source: Bettini, Crockett, Brownell, \& Merrill, 2016.

stronger student achievement gains (Bryk \& Schneider, 2002; Goddard et al., 2015; Hoy et al., 2006; Ronfeldt et al., 2015).

Fewer studies have examined how school cultures contribute to the instructional quality and effectiveness of special education teachers. However, there is reason to believe that, because SETs rely on collaboration with their colleagues, school culture may be especially important for their ability to effectively serve students with disabilities (Jones, Youngs, \& Frank, 2013). For example, Jones and colleagues determined that a school's culture of collective responsibility significantly predicted new SETs' intentions to continue teaching, whereas it was unrelated to new general educators' intentions. Similarly, Bettini (2015) reported new SETs' perceptions of workload manageability were significantly predicted by their school's culture of collective responsibility, but collective responsibility was unrelated to new general educators' perceptions of workload manageability.

A handful of studies reveal that students with disabilities make stronger academic achievement gains when their schools and districts have cultures of high expectations and shared responsibility for their learning (Bettini, Benedict, Thomas, Kimerling, Choi, \& McLeskey, in press; Edmonds \& Spradlin, 2010; Nagle, Hernandez, Embler, McLaughlin, \& Doh, 2006). However, none of these studies articulated mechanisms by which these school cultures led to improvements in the achievement of students with disabilities, and future studies are needed to explore how school culture may contribute to their positive outcomes.
For example, did these cultures promote stronger instruction among special and general educators? Did they promote better coordination of instruction across classes? What role did well-supported inclusive instruction play in students' stronger achievement?

\section{Administrative Support}

School effectiveness research consistently confirms that highly skilled school leaders are essential for teachers' retention (Beteille, Kalogrides, \& Loeb, 2012; Grissom, 2011; Ladd, 2009), and that teachers' perceptions of administrative support explain a significant proportion of the variance in their schools' effectiveness at promoting student achievement gains (Goddard et al., 2015; Johnson et al., 2012; Ladd, 2009). Within special education, researchers consistently find SETs are significantly more likely to intend to stay in their schools and districts when they feel well supported by their administrators (Albrecht et al., 2009; Billingsley, 2004; Cross \& Billingsley, 1994). For example, in surveying the intentions of 776 SETs and related service providers serving students with emotional disturbance, Albrecht et al. determined SETs with daily administrative support were significantly more likely to stay for the next 2 years, whereas SETs who experienced administrative support "on request" were significantly more likely to leave. Overall ratings of administrative support were significantly higher for those SETs intending to stay. Studies using path analysis studies have similarly found that higher levels of support from principals are directly or indirectly associated with greater 
job satisfaction, fewer role problems, reduced stress, and higher levels of SET commitment (Cross \& Billingsley, 1994; Gersten et al., 2001; Singh \& Billingsley, 1996). Some scholars have hypothesized that, because SETs rely on collaboration and coordination of instruction across the school, and because their roles are sometimes ambiguously defined, they may in fact rely on supportive administrators even more than general educators (Youngs et al., 2011). However, no extant research has tested this hypothesis.

To date, only one study has examined how administrative support influences the instruction of special educators. Bishop, Brownell, Klingner, Leko, and Galman (2010) interviewed 25 beginning SETs and observed their reading instruction. Their findings revealed that beginning SETs, who reported their administrators gave instructionally focused support, provided more effective reading instruction than beginning SETs who reported their administrators supported them emotionally or supported them by leaving them alone. No other studies provide insights into how administrators support SETs in improving their instruction for students with disabilities.

\section{Collegial Support}

To our knowledge, Bishop et al.'s (2010) investigation is also the only study to have explored the relationship between collegial support and instructional quality among SETs. Their analysis revealed that beginning SETs who scored more highly on an observation tool also reported experiencing instructionally focused support from their colleagues, whereas SETs who scored lower reported experiencing no support, or purely emotional/organizational support. More research is needed to understand how collegial supports may contribute to SETs' learning and enactment of effective instructional practices.

A stronger body of research indicates that collegial support may contribute to the quality of the SET workforce by increasing retention rates (Billingsley, 2004). Studies consistently find that SETs are more likely to stay if they perceive that their colleagues and administrators are supportive (Albrecht et al., 2009; Billingsley, 2004; Jones et al., 2013). For example, Jones and colleagues' found new SETs' ratings of the usefulness of collegial support significantly predicted their intentions to continue teaching in their schools. This relationship, however, was not significant for new general educators (Jones et al., 2013).

Collegial support may be especially important for SETs in inclusive schools (Billingsley et al., 2009). OtisWilborn, Winn, Griffin, and Kilgore (2005) found new SETs' efforts to include students with disabilities were often made more difficult by their colleagues' failure to take responsibility for the learning of students with disabilities. Across new teacher studies, many SETs struggled to include their students in general classrooms, citing difficulties with collaboration, lack of scheduled time, and isolation from colleagues. Consequently supporting new SETs in their collaborative work is essential given the importance of teacher collaboration for meeting the needs of students in inclusive settings (McCray, Butler, \& Bettini, 2014).

\section{Material Resources}

Special educators' access to material resources for instruction may contribute to both their instructional quality and their retention (Albrecht et al., 2009; Bettini, Crockett et al., 2016). Albrecht et al. reported that SETs who had good/excellent access to instructional resources were more likely to intend to continue teaching than SETs who reported less access to instructional resources.

There is also some evidence that material resources can contribute to instructional quality (Bishop et al., 2010; Brownell, Lauterbach et al., 2014; Dingle, Brownell, Leko, Boardman, \& Hagar, 2011; Otis-Wilborn et al., 2005). SETs have reported that inadequate access to instructional resources can be a substantial barrier to their efforts to provide strong instruction (Otis-Wilborn et al., 2005), and several studies indicate curricular materials can shape how teachers negotiate choices about what content to address during their instruction (Brownell, Lauterbach et al., 2014; Dingle et al., 2011). For instance, Brownell, Lauterbach, and colleagues (2014) determined that curricular materials influenced how SETs negotiated choices about which content (e.g. intervention instruction, support for general education curricula) to teach during their limited time with students. Bishop and colleagues (2010) found highly accomplished beginning SETs were more likely to have easy access to instructional materials than their less accomplished colleagues. The authors hypothesized that instructional materials may have supported new SETs in providing strong instruction; however, they also noted that the most accomplished beginners actively sought out resources, whereas less skilled SETs tended to use the materials they were provided, regardless of the quality of those materials. Bishop and colleagues concluded that beginners' personal qualities interacted with their access to material resources, in complex ways that influenced their instruction.

\section{Instructional Grouping}

Small, homogeneous instructional groups may support SETs' instructional quality by facilitating their efforts to individualize and intensify instructional interventions (Bettini, Crockett et al., 2016). Three literature reviews have examined how instructional grouping contributes to the effectiveness of SETs' instruction. Two of these reviews revealed that, when instructional groups are smaller and more homogeneous (in terms of students' learning needs), SETs may promote more positive student outcomes (Russ, Chiang, Rylance, \& Bongers, 2001; Wanzek \& Vaughn, 2007). Russ and colleagues (2001) reviewed studies across a range of different ages, disability categories, and interventions concluding that SETs who teach small, homogeneous instructional groups are more effective in promoting students' engagement and 
achievement. Wanzek and Vaughn's (2007) review examined studies of K-3 reading interventions, leading the authors to conclude that interventions with smaller groups were more effective in promoting students' reading growth. In contrast, Wanzek et al. (2013) reviewed reading interventions in Grades 4-12, finding no differences in the effectiveness of interventions with different group sizes, possibly because effects for reading interventions in upper grades are often small.

\section{Instructional Time}

Recent research suggests that SETs actually spend a minority of their time providing instruction. Vannest and Hagan-Burke (2010) found on average, SETs in their study only spent $35 \%$ of their time providing academic instruction, nonacademic instruction, and instructional support, combined. Other studies have obtained similar estimates (Bettini, Kimerling, Park, \& Murphy, 2015; Mitchell, Deshler, \& Lenz, 2012). These studies consistently find that a large proportion of SETs' time is spent supervising students during non-instructional activities (e.g. bus duty, lunch duty, etc.), planning and preparing for instruction, completing paperwork, and managing disciplinary issues (Bettini et al., 2015; Mitchell et al., 2012; Vannest \& Hagan-Burke, 2010).

Some studies suggest that, when SETs have limited time allocated for instructing their students, they may struggle to negotiate competing instructional demands (e.g. supporting general education curricula vs. providing intervention instruction), and thus may provide their students with less coherent and skilled instruction (Brownell, Lauterbach et al., 2014; Vannest, Soares, Harrison, Brown, \& Parker, 2010). For example, Brownell and colleagues found some participants struggled to implement content learned through professional development because extremely limited instructional time was split amongst intervention instruction, preparation for testing, and supporting general education curricula.

It should be noted that Vannest and colleagues (2010) determined that SETs may have little control over how their time is allocated. They used logs to measure SETs' instructional time, and then met with teachers to provide them with formative data about their time use, to help them set goals for improving instructional time, and develop strategies for meeting these goals. The assumption underlying this study was that, with performance feedback and clear goals, SETs would be able to increase time they devoted to instruction. No SETs were able to make meaningful changes in the proportion of time devoted to instruction. In interviews, SETs reported having little control over their time, as a result of limited planning time, paperwork responsibilities, diverse instructional groups, and extra tasks, such as supervising students. Participants reported that, as a result of limited time to engage in all of their responsibilities, they sometimes used instructional time to plan, complete paperwork, and fulfill extra tasks.

\section{Planning Time}

Scholars have posited that assigned planning time may provide teachers with a necessary opportunity to carefully plan and improve instruction, and thus may be important for both developing lessons and for teacher learning (Darling-Hammond, Wei, Andree, Richardson, \& Orphanos, 2009). Planning time may also contribute to retention by providing teachers with sufficient time in which to fulfill all of their responsibilities, thus helping them feel that their workloads are more manageable (Vannest et al., 2010). However, few studies have examined empirically how planning time contributes to retention or to instructional quality (Bettini, Crockett et al., 2016). Allinder (1996), for example, investigated working conditions associated with the quality of 19 SETs' implementation of CBM procedures in elementary mathematics classes. Their findings revealed perceptions of the adequacy of planning time significantly differentiated SETs who implemented CBM with high fidelity from those with low fidelity. Allinder posited that planning time may be essential for the implementation of new practices, providing time for SETs to integrate new practices within their instructional repertoire.

Collaborative planning time may be especially important for SETs working in inclusive settings, as they must support their students' success in all tiers of instruction. Scruggs and colleagues (2007) synthesized 32 qualitative studies of co-teaching, finding that across studies, SETs were often relegated to a subordinate role within co-taught classrooms, acting as assistants rather than primary providers of instruction. Across studies, SETs reported that lack of collaborative planning time contributed to their subordinate role; when they were unable to have a voice in developing lesson plans during collaborative planning, they were not able to assume instructional roles that were as meaningful or substantive as general educators' roles (Scruggs et al., 2007).

\section{Work Assignments and Role Problems}

Well-designed work - work that is meaningful, internally coherent, and reasonable in scope - provides teachers with a sense of purpose and allows them to work toward valued goals (Gersten et al., 2001). However, research on special educators' roles indicates that substantial role problems often complicate and undermine special educators' efforts to craft and fulfill meaningful roles within their schools (Billingsley, 2004; Gersten et al., 2001).

SETs experience role overload when they are assigned more responsibilities than can be reasonably completed well with the time and resources available (Billingsley, 2004). Studies consistently find that SETs' career intentions are predicted by indicators of role overload (Cross \& Billingsley, 1994), such as adequacy of time to complete paperwork, the manageability of their workloads (Bettini, Jones et al., 2016), and time and materials to meet job demands. Part of this may be do to recent research indicating that caseloads may be on the rise 
(Dewey et al., in press), requiring more instruction, coordination with others, and paperwork. Findings from Vannest and Hagan-Burke (2010) illustrate the problem of varied role demands revealing that SETs only spend a minority of their time providing instruction. Instead, they spend a substantial portion of their work lives engaging in other responsibilities, such as supervision and paperwork that do not require their specialized skills, leading the authors to ask, "Is a SPED teacher a teacher?" (p. 126)

Role overload may lead to role conflict, as teachers allocate their time to management and paperwork tasks, rather than teaching. Another challenge concerns role ambiguity, meaning the lack of necessary information about the scope and boundaries of their role, and how they should go about fulfilling that role (Otis-Wilborn et al., 2005; Youngs et al., 2011). Youngs and colleagues (2011) described how new SETs found their responsibilities to be ambiguous and received less guidance than GETs about their roles. Prior studies suggest that role problems contribute to stress and decreased job satisfaction and commitment among special educators (Cross \& Billingsley, 1994; Gersten et al., 2001).

\section{Summary and Discussion}

Educational leaders need to consider the extent to which SETs have opportunities to plan and teach effectively. Gersten et al. (2001) posed the following questions: "Does the job, with all it entails, make sense? Is it feasible? Is it one that well trained, interested, special education professionals can manage in order to accomplish their main objective - enhancing students' academic, social, and vocational competence?" (p. 551). School leaders should carefully examine what they ask SETs to do, asking whether the responsibilities are reasonable within the time allotted and whether they provide adequate supports to help SETs fulfill those responsibilities. Administrators should engage in open dialogue with SETs, seeking to understand (without judgment) how much time various responsibilities take and what additional supports SETs may need to fulfill those responsibilities (Bettini, Benedict et al., 2016).

\section{Conclusions}

Securing, cultivating and keeping an effective special education teacher workforce is an essential responsibility for policy-makers and school leaders. Clearly much more needs to be learned about promoting SET effectiveness and how teacher characteristics, preparation, practices and conditions of work impact the outcomes of students with disabilities. Figure 33.1 proposes that a complex array of factors interact to influence the extent to which students with disabilities have access to skilled and committed teachers. The interaction among teacher quality factors can combine to provide students with academically talented, well-prepared SETs who teach in supportive work contexts and engage in ongoing learning opportunities.
In contrast, these factors may interact such that students are exposed to minimally prepared teachers with poor working conditions, leaving these students with fewer opportunities to learn. Given the evidence that the latter scenario is consistent with some high poverty schools, policy-makers need to consider solutions that will address these inequities. It is unlikely that the SET workforce will improve without a comprehensive, strategic and wellcoordinated plan and significant investments in teachers. Leaders at the school and districts levels should assess local conditions through periodical assessments and strategically allocate scarce resources where they are likely to make the greatest difference.

\section{References}

Abbott, M., Greenwood, C. R., Buzhardt, J., \& Tapia, Y. (2006). Using technology-based teacher support tools to scale up the classwide peer tutoring program. Reading \& Writing Quarterly, 22(1), 47-64.

Achinstein, B., Ogawa, R. T., Sexton, D., \& Freitas, C. (2010). Retaining teachers of color: A pressing problem and a potential strategy for "hard to staff" schools. Review of Educational Research, 80, 71-107. doi: 10.3102/0034654309355994

Adnot, M., Dee, T., Katz, V., \& Wyckoff, J. (2016). Teacher turnover, teacher quality and student achievement in DCPS. Washington DC: National Center for Analysis of Longitudinal Data in Education Research. Retrieved from www.caldercenter.org/publications/ teacher-turnover-teacher-quality-and-student-achievement-dcps.

Al Otaiba, S. (2005). How effective is code-based reading tutoring in English for English learners and preservice teacher-tutors? Remedial and Special Education, 26, 245-254. doi:10.1177/0741932505026 0040701

Albrecht, S. F., Johns, B. H., Mountstevens, J., \& Olorunda, O. (2009). Working conditions as risk or resiliency factors for teachers of students with emotional and behavioral disabilities. Psychology in the Schools, 10, 1006-1022.

Alexander, M., Lignugaris-Kraft, B., \& Forbush, D. (2007). Online mathematics methods course evaluation: Student outcomes, generalization, and pupil performance. Teacher Education and Special Education, 30, 199-216. doi:10.1177/088840640703000401

Allinder, R. M. (1996). When some is not better than none: Effects of differential implementation of curriculum-based measurement. Exceptional Children, 62, 525-535.

Baker, S., Gersten, R., Dimino, J. A., \& Griffiths, R. (2004). The sustained use of research based instructional practice. Remedial and Special Education, 25(1), 5-24.

Benedict, A. E. (2014). Learning together: General and special education teachers' evolving understandings of word study content during ongoing collaborative professional development (unpublished doctoral dissertation). Gainesville, FL: University of Florida.

Benedict, A. E., Park, Y., Brownell, M. T., Lauterbach, A. A., \& Kiely, M. T. (2013). Using lesson study to align elementary literacy instruction within the RTI framework. TEACHING Exceptional Children, 45(5), 22-30.

Berry, A. B., Petrin, R. A., Gravelle, M. L., \& Farmer, T. W. (2012). Issues in special education teacher recruitment, retention, and professional development: Considerations in supporting rural teachers. Rural Special Education Quarterly, 30, 3-11.

Beteille, T., Kalogrides, D., \& Loeb, S. (2012). Stepping stones: Principal career paths and school outcomes. Social Science Research, 41, 904-919.

Bettini, E. (2015). Novice special educators' perceptions of workload manageability: Do they matter and are they influenced by novices' perceptions of their social context? Unpublished dissertation, University of Florida. 
Bettini, E., Benedict, A., Thomas, R., Kimerling, J., Choi, N., \& McLeskey, J. (2016, accepted for publication). Cultivating a community of effective special educators: Local special education administrators' roles. Remedial and Special Education.

Bettini, E. A., Crockett, J., Brownell, M. T., \& Merrill, K. (2016). Relationships between working conditions and special educators' instruction. Journal of Special Education, 50, 178-290.

Bettini, E., Jones, N. D., Brownell, M. T., Conroy, M., Park, Y., Leite, W., ... Benedict, A. E. (forthcoming). Workload manageability among novice special and general educators: Relationships with emotional exhaustion and career intentions.

Bettini, E., Kimerling, J., Park, Y., \& Murphy, K. (2015). Responsibilities and instructional time: Relationships identified by special educators in self-contained classes for students with emotional and behavioral disabilities. Preventing School Failure, 39, 121-128. doi: http:// dx.doi.org/10.1080/1045988X.2013.859561

Billingsley, B. (2004). Special education teacher retention and attrition: A critical analysis of the research literature. The Journal of Special Education, 38(1), 39-55.

Billingsley, B. (2007). Recognizing and supporting the critical roles of teachers in special education leadership. Exceptionality, 15(3), $163-176$.

Billingsley, B., Carlson, E., \& Klein, S. (2004). The working conditions and induction support of early career special educators. Exceptional Children, 70(3), 333-347.

Billingsley, B., Fall, A., \& Williams, T. O. (2006). Who is teaching students with emotional disorders? A profile and comparison to other special educators. Behavioral Disorders, 31(1), 252-264.

Billingsley, B., Griffin, C., Smith, S.J., Kamman, M., \& Israel, M. (2009). $A$ review of teacher induction in Special Education: Research, Practice, and Technology Solutions. Monograph prepared for the National Center to Inform Policy and Practice in Special Education Professional Development (NCIPP), The University of Florida.

Billingsley, B. \& Williams (2016). Teacher induction: A comparison of special and general educators. Manuscript submitted for publication.

Bishop, A. G., Brownell, M. T., Klingner, J. K., Leko, M. M., \& Galman, S. A. C. (2010). Differences in beginning special education teachers: The influence of personal attributes, preparation, and school environments on classroom reading practices. Learning Disability Quarterly, 33, 75-92. doi:10.1177/073194871003300202

Boe, E. E. (2006). Long term trends in the national demand, supply, and shortage of special education teachers. Journal of Special Education, 40, 138-150.

Boe, E. E., \& Cook, L. H. (2006). The chronic and increasing shortage of fully certified teachers in special and general education. Exceptional Children, 72(4), 443-460.

Boe, E. E., Cook, L. H., \& Sunderland, R. J. (2007a). The prevalence of various aspects of teacher preparation, induction, mentoring, extra support, professional development, and workload factors for beginning teachers in special and general education (Data Analysis Report No. 2007-DAR1). Philadelphia, PA: University of Pennsylvania, Graduate School of Education, Center for Research and Evaluation in Social Policy.

Boe, E. E., Cook, L. H., \& Sunderland, R. J. (2007b). Trends in the turnover of teachers from 1991 to 2004: Attrition, teaching area transfer, and school migration (Data Analysis Report No. 2007-DAR2). Philadelphia, PA: University of Pennsylvania, Graduate School of Education, Center for Research and Evaluation in Social Policy.

Boe, E. E., Cook, L. H., \& Sunderland, R. J. (2008a). Teacher turnover: Examining exit attrition, teaching area transfer, and school migration. Exceptional Children, 75, 7-31.

Boe, E. E., Cook, L. H., \& Sunderland, R. J. (2008b). Teacher qualifications and turnover: Bivariate associations with various aspects of teacher preparation, induction, mentoring, extra support, professional development, and workload factors for early career teachers in special and general education (Data Analysis Rep. 2008-DAR1). Philadelphia, PA: University of Pennsylvania, Graduate School of Education, Center for Research and Evaluation in Social Policy.
Boe, E. E., de Bettencourt, L. U., Dewey, J., Rosenberg, M., Sindelar, P., \& Leko, C. (2013). Variability in demand for special education teachers: Indicators, explanations, and impacts. Exceptionality, 21, 103-125. doi:10.1080/09362835.2013.771563

Boyd, D., Grossman, P., Lankford, H., Loeb, S., \& Wyckoff, J. (2008). Who leaves? Teacher attrition and student achievement (Working Paper 14022). Cambridge, MA: National Bureau of Economic Research. Retrieved from www.nber.org.

Boyd, D. J., Grossman, P. L., Lankford, H., Loeb, S., \& Wyckoff, J. (2009). Teacher preparation and student achievement. Educational Evaluation and Policy Analysis, 31(4), 416-440. doi: 10.3102/0162 373709353129

Brooks, W., Kaimal, G., Savage, L., \& Gonzaga, A. (2012). Inspiring academically talented high school students to consider teaching careers in urban schools. Urban Review, 44, 423-440.

Brownell, M. T., Bishop, A., Gersten, R., Klingner, J. K., Penfield, R. D., Dimino, J., ... Sindelar, P. (2009). The role of domain expertise in special education teacher quality, Exceptional Children, 75(4), 391-411.

Brownell, M. T., \& Jones, N. (2015). Teacher evaluation in special education: Potential approaches, supporting research, and challenges confronted. The Journal of Special Education Leadership, 28, 63-73.

Brownell, M. T., Kiely, M. T., Haager, D. A., Boardman, A. G., Corbett, N., Algina, J., . . . Urbach, J. (2016). Literacy learning cohorts: Contentfocused approach to improving special Education teachers' reading instruction. Exceptional Children, 83, 143-164.

Brownell, M. T., Lauterbach, A. A., Dingle, M. P., Boardman, A. G., Urbach, J. E., Leko, M., . . Park, Y. P. (2014). Individual and contextual factors influencing special education teacher learning in literacy learning cohorts. Learning Disability Quarterly, 37, 31-44. doi: http://dx.doi.org/10.1177/0731948713487179

Brownell, M. T., Sindelar, P. T., Kiely, M. T., \& Danielson, L. C. (2010). Special education teacher quality and preparation: Exposing foundations, constructing a new model. Exceptional Children, 76, 357-377.

Brownell, M. T., Steinbrecher, T., Kimerling, J., Park, Y., Bae, J., \& Benedict, A. (2014). Dimensions of teacher quality in general and special education. In P. T. Sindelar, E. D. McCray, M. T. Brownell, \& B. Lignugaris-Kraft (Eds.), Handbook of research on special education teacher preparation (pp. 423-444). New York, NY: Routledge.

Brunsting, N., Sreckovic, M., \& Lane, K. L. (2014). Special education teacher burnout: A synthesis of research from 1979 to 2013. Education and Treatment of Children, 37, 681-711.

Bryk, A., \& Schneider, B. (2002). Trust in schools: A core resource for improvement. New York, NY: Russell Sage Foundation.

Buzick, H. M. \& Laitusis, C. C. (2010). A summary of models and standards-based applications for grade-to-grade growth on statewide assessments and implications for students with disabilities. Retrieved January 27, 2017 from www.ets.org/research/contact.html

Carlson, E., \& Billingsley, B. (2010). Workforce issues in special education, in B. McGaw, Peterson, P. \& Baker, E., International Encyclopedia of Education (pp. 886-891). Amsterdam: Elsevier.

Carlson, E., Lee, H., \& Schroll, K. (2004). Identifying attributes of high quality special education teachers. Teacher Education and Special Education, 27(4), 350-359.

Chetty, R., Friedman, J. N., \& Rockoff, J. E. (2012), The long-term impacts of teachers: Teacher value added and student outcomes in adulthood. Cambridge, MA: National Bureau of Economic Research. Retrieved January 27, 2017 from www.nber.org

Clotfelter, C. T., Ladd, H. F., \& Vigdor, J. L. (2010). Teacher credentials and student achievement in high school: A cross-subject analysis of student fixed effects. The Journal of Human Resources, $45,655-681$

Cochran-Smith, M., \& Villegas, A. M. (2015). Framing teacher preparation research: An overview of the field, Part 1. Journal of Teacher Education, 66(1), 7-20.

Cook, B., \& Schirmer, B. (2003). What is special about special education? Overview and analysis. The Journal of Special Education, $37(3), 200-205$. 
Cross, L., \& Billingsley, B. (1994). Testing a model of special educators' intent to stay in teaching. Exceptional Children, 60(5), 411-421.

Darling-Hammond, L., Wei, R. C., Andree, A., Richardson, N., \& Orphanos, S. (2009). Professional learning in the learning profession: A status report on teacher development in the United States and abroad. National Staff Development Council and the School Redesign Network. Retrieved January 27, 2017 from: http://learn ingforward.org/.

DeAngelis, K. J., Wall, A. F., \& Che, J. (2013). The impact of preservice preparation and early career support on novice teachers' career intentions and decisions. Journal of Teacher Education, 64, 338-355.

Desimone, L. M. (2009). Improving impact studies of teachers' professional development: Toward better conceptualizations and measures, Educational Researcher, 38(3), 181-199.

Dewey, J., Sindelar, P., Bettini, E., Leko, C., Boe, E., \& Rosenberg, M. (in press). Declining special education teacher employment, 2005-2012. Exceptional Children.

Dieker, L. A., Hynes, M. E., Hughes, C., \& Straub, C. (2014). Using virtual rehearsal in TLE TeachLivE ${ }^{\mathrm{TM}}$ mixed reality classroom simulator to determine the effects on the performance of mathematics teachers (Technical Report), Orlando: University of Central Florida.

Dieker, L. A., Kennedy, M. J., Smith, S., Vasquez III, E., Rock, M., \& Thomas, C. N. (2014). Use of technology in the preparation of preservice teachers (Document No. IC-11). Retrieved January 27, 2017 from University of Florida, Collaboration for Effective Educator, Development, Accountability, and Reform Center website: http:// ceedar.education.ufl.edu/tools/innovation-configurations/

Dieker, L. A., Lane, H. B., Allsopp, D. H., O’Brien, C., Butler, T. W., Kyger, M., ... Fenty, N. S. (2009). Evaluating video models of evidence-based instructional practices to enhance teacher learning. Teacher Education and Special Education, 32, 180-196. doi:10. 1177/0888406409334202

Dingle, M. P., Brownell, M. T., Leko, M. M., Boardman, A. G., \& Hagar, D. (2011). Developing effective special education reading teachers: The influence of professional development, context, and individual qualities. Learning Disability Quarterly, 34, 87-103.

Edmonds, B. C., \& Spradlin, T. (2010). What does it take to become a high-performing special education planning district?: A study of Indiana's special education delivery service system. Remedial and Special Education, 31, 320-329.

Englert, C. S., \& Rozendal, M. S. (2004). A model of professional development in special education. Teacher Education and Special Education, 27(1), 24-46.

Fall, A. M., \& Billingsley, B. (2008). Disparities in teacher quality among early career special educators in high and low poverty districts. In T. E. Scruggs \& M. A. Mastropieri (Eds.), Advances in learning and behavioral disabilities: Vol. 21. Personnel preparation (pp. 181-206). Stanford, CT: JAI

Fall, A. M., \& Billingsley, B. (2011). Disparities in work conditions among early career special educators in high- and low-poverty districts, Remedial and Special Education, 32(1), 64-78.

Feng, L., \& Sass, T. R. (2013). What makes special-education teachers special? Teacher training and achievement of students with disabilities. Economics of Education Review, 36, 122- 134.

Gehrke, R. S., \& Murri, N. (2006). Beginning special educators' intent to stay in special education: Why they like it here. Teacher Education and Special Education, 29(3), 179-190.

Gersten, R., Dimino, J., Jayanthi, M., Kim, J. S., \& Santoro, L. E. (2010). Teacher study group: Impact of the professional development model on reading instruction and student outcomes in first grade classrooms. American Educational Research Journal, 47, 694-739.

Gersten, R., Keating, T., Yovanoff, P., \& Harniss, M. K. (2001). Working in special education: Factors that enhance special educators' intent to stay. Exceptional Children, 67(4), 549-567.

Glazerman, S., Isenberg, E. Dolfin, S., Bleeker, M., Johnson, A., Grider, M., \& Jacobus, M. (2010). Impacts of comprehensive teacher induction: Final results from randomized controlled study (NCEE 2010-4027). Washington, DC: National Center for Education Evaluation and Regional Assistance, Institute of Education Sciences, U. S. Department of Education. Retrieved January 27, 2017 from http://ies.ed.gov/ncee/pubs/20104027/ pdf/20104027.pdf

Goddard, R., Goddard, Y., Kim, E. S., \& Miller, R. (2015). A theoretical and empirical analysis of the roles of instructional leadership, teacher collaboration, and collective efficacy beliefs in support of student learning. American Journal of Education, 121, 501-529.

Goe, L. Bell, C., \& Little, O. (2008). Approaches to evaluating teacher effectiveness: A research synthesis. National Comprehensive Center for Teacher Quality, Washington, DC. Retrieved January 27, 2017 from www.tqsource.org/publications/EvaluatingTeachEffectiveness.pdf

Grissom, J. A. (2011). Can good principals keep teachers in disadvantaged schools?: Linking principal effectiveness to teacher satisfaction and turnover in hard-to-staff environments. Teachers College Record, 113, 2552-2585.

Grossman, P., \& Thompson, C. (2004). District policy and beginning teachers: A lens on teacher learning. Educational Evaluation and Policy Analysis, 26, 281-301.

Grossman, P., \& Thompson, C. (2008). Learning from curriculum materials: Scaffolds for new teachers? Teaching and Teacher Education, 24, 2014-2026.

Guarino, C. M., Santibanez, L., \& Daley, G. A. (2006). Teacher recruitment and retention: A review of the recent empirical literature. Review of Educational Research, 76(2), 173-208.

Hiebert, J., \& Morris, A. K. (2012). Teaching, rather than teachers, as a path toward improving classroom instruction. Journal of Teacher Education, 63, 92-102.

Hoy, W. K., Tarter, C. J., \& Hoy, A. W. (2006). Academic optimism of schools: A force for student achievement. American Educational Research Journal, 43, 425-446. doi: http://dx.doi.org/10.3102/0002 8312043003425

Hunt, J. H., Powell, S., Little, M. E., \& Mike, A. (2013). The effects of e-mentoring on beginning teacher competencies and perceptions. Teacher Education and Special Education, 36, 286-297.

Ingersoll, R. M., \& Strong, M. (2011). The impact of induction and mentoring programs for beginning teachers: A critical review of research. Review of Educational Research, 81, 201-233. doi: http://dx.doi. org/10.3102/0034654311403323

Israel, J., Kamman, M. L, McCray, E. D., \& Sindelar, P. T. (2014). Mentoring in action: The interplay among professional assistance, emotional support, and evaluation. Exceptional Children, 81(1), 45-63.

Jackson, K., \& Bruegmann, E. (2009). Teaching standards and teaching each other: The importance of peer learning for teachers. American Economic Journal: Applied Economics, 1, 85-108. doi: http://dx.doi. org/10.1257/app.1.4.85

Johnson, S. M., Kardos, S. M., Kauffman, D., Liu, E., \& Donaldson, M. L. (2004). The support gap: New teachers' early experiences in high-income and low-income schools. Education Policy Analysis Archives, 12(61). Retrieved from http://epaa.asu.edu/epaa/v12n61/.

Johnson, S. M., Kraft, M. A., \& Papay, J. P. (2012). How context matters in high-need schools: The effect of teachers' working conditions on their professional satisfaction and their students' achievement. Teachers College Record, 114, 1-39.

Jones, N. D., Bettini, E., \& Brownell, M. T. (April, 2016). Competing strands of educational reform policy: Can collaborative school reform and teacher evaluation reform be reconciled?. Albert Shanker Institute. Retrieved January 27, 2017 from www.shankerinstitute.org.

Jones, N. D. \& Brownell, M. T. (2014). Examining the use of classroom observations in the evaluation of special education teachers. Assessment for Effective Intervention, 39, 112-124.

Jones, N. D., Buzick, H. M., \& Turkan, S. (2013). Including students with disabilities and English learners in measures of educator effectiveness. Educational Researcher, 42, 234-241. doi: http://dx.doi. org/10.3102/0013189X12468211

Jones, N. D., Youngs, P., \& Frank, K. A. (2013). The role of schoolbased colleagues in shaping the commitment of novice special and general education teachers. Exceptional Children, 79, 365-383. 
Kalogrides, D., Loeb, S., \& Beteille, T. (2013). Systematic sorting: Teacher characteristics and class assignments. Sociology of Education, 86(2), 103-123.

Kamman, M., \& Long, S. K. (2010). One district's approach to the induction of special education teachers The Journal of Special Education Leadership, 23(1), 21-29.

Kardos, S. M., \& Johnson, S. M. (2010). New teachers' experiences of mentoring: The good, the bad, and the inequity. Journal of Educational Change, 11, 23-44.

Kennedy, M. J., Hart, J. E., \& Kellems, R. O. (2011). Using enhanced podcasts to augment limited instructional time in teacher preparation. Teacher Education and Special Education, 34, 87-105. doi: 10. 1177/0888406410376203

Klingner, J. K., Ahwee, S., Pilonieta, P., \& Menendez, R. (2003). Barriers and facilitators in scaling up research-based practices. Exceptional Children, 69(4), 411-429.

Klingner, J. K., Arguelles, M., Hughes, M., \& Vaughn, S. (2001). Examining the schoolwide "spread" of research-based practices. Learning Disability Quarterly, 24(4), 221-234.

Kraft, M. A. \& Papay, J. P. (2014). Can professional environments in schools promote teacher development?: Explaining heterogeneity in returns to teaching experience. Educational Evaluation and Policy Analysis, 36, 476-500. doi: http://dx.doi.org/10.3102/01623 73713519496

Ladd, H. (2009). Teachers' perceptions of their working conditions: How predictive of policy-relevant outcomes (Working Paper 33). National Center for Analysis of Longitudinal Data in Education Research. Retrieved January 27, 2017 from www.caldercenter.org.

Leko, M. M., Brownell, M. T., Sindelar, P. T., \& Kiely, M. T. (2015). Envisioning the future of special education personnel preparation in a standards-based era. Exceptional Children, 82, 25-43.

Levin, J., Berg-Jacobsen, A., Atchinson, D., Lee, K., \& Vontsolos, E. (2015). Massachusetts study of teacher supply and demand: Trends and projections. American Institutes for Research. Retrieved February 5, 2017 from www.air.org/resource/massachusetts-studyteacher-supply-and-demand-trends-and-projections.

López-Estrada, V., \& Koyama, M. (2010). Retaining Mexican American special education teachers in Texas. Journal of Hispanic Higher Education, 9, 82-97.

McCray, E. D., Butler, T. W., \& Bettini, E. (2014). Sharing expertise and shifting expectations: The roles of general and special educators in effective, inclusive schools. In J. McLeskey, N. L. Waldron, F. Spooner, \& B. Algozzine (Eds.) Handbook of Research for Effective, Inclusive Schools (pp. 80-93). New York, NY: Routledge.

McLaughlin, M. J. (2010). Evolving interpretations of educational equity and students with disabilities. Exceptional Children, 76(3), 265-278. doi: http://dx.doi.org/10.1177/001440291007600302

McLeskey, J., \& Billingsley, B. S. (2008). How does the quality and stability of the teaching force influence the research-to-practice gap? A perspective on the teacher shortage in special education. Remedial and Special Education, 29(5), 293-305.

McLeskey, J., Tyler, N., \& Flippin, S. S. (2004). The supply of and demand for special education teachers: A review of research regarding the nature of the chronic shortage of special education teachers. The Journal of Special Education, 38(1), 5-21.

Mallette, B., Maheady, L., \& Harper, G. F. (1999). The effects of reciprocal peer coaching on preservice general educators' instruction of students with special learning needs. Teacher Education and Special Education, 22, 201-216. doi: 10.1177/088840649902200402

Mangin, M. M. \& Stoelinga, S. R. (2008). Effective teacher leadership: Using research to inform and reform. New York, NY: Teachers College Press

Mason-Williams, L., \& Gagnon, J. (2016). Prepared to meet whose needs?: Teacher sorting in special education and alternative schools. Journal of Special Education, 50, 239-250.

Mason-Williams, L. (2015). Unequal opportunities: A profile of the distribution of special education teachers. Exceptional Children, 81(2), 247-262. doi: 10.1177/0014402914551737
Mathur, S. R., Gerhke, R., \& Kim, S. H. (2013). Impact of a teacher mentorship program on mentors' and mentees' perceptions of classroom practices and the mentoring experience. Assessment for Effective Intervention, 38, 154-162.

Milanowski, A. T., \& Odden, A. R. (2007). A new approach to the cost of teacher turnover (Working Paper 13). The School Finance Redesign Project. Retrieved January 27, 2017 from www.schoolfinancerede sign.org.

Miller, M. D., Brownell, M., \& Smith, S. W. (1999). Factors that predict teachers staying in, leaving, or transferring from the special education classroom. Exceptional Children, 65(2), 201-218.

Mitchell, B. B., Deshler, D. D., \& Lenz, B. K. B. H. (2012). Examining the role of the special educator in a response to intervention model. Learning Disabilities, 10, 53-74.

Mutch-Jones, K., Puttick, G., \& Minner, D. (2012). Lesson study for accessible science: building expertise to improve practice in inclusive science classrooms. Journal of Research in Science Teaching, 49(8), 1012-1034

Nagle, K. M., Hernandez, G., Embler, S., McLaughlin, M. J., \& Doh, F. (2006). Characteristics of effective rural elementary schools for students with disabilities. Rural Special Education Quarterly, 25, 3-12.

National Coalition on Personnel Shortages in Special Education and Related Services (n.d.). Retrieved February 5, 2016 from: http://spe cialedshortages.org/about-the-shortage/

Nougaret, A. A., Scruggs, T. E., \& Mastropieri, M. A. (2005). Does teacher education produce better special education teachers? Exceptional Children, 71(3), 217-229.

Otis-Wilborn, A., Winn, J., Griffin, C., \& Kilgore, K. (2005). Beginning special educators' forays into general education. Teacher Education and Special Education, 28(3/4), 143-152.

Pugach, M. C., \& Blanton, L. P. (2009). A framework for conducting research on collaborative teacher education, Teaching and Teacher Education, 25, 575-582.

Pugach, M. C., Blanton, L. P., Correa, V. I., McLeskey, J., \& Langley, L. K. (2009). The role of collaboration in supporting the and retention of new special education teachers (NCIPP Doc. No. RS-2). University of Florida, National Center to Inform Policy and Practice in Special Education Professional Development.

Rivkin, S., Hanushek, E., \& Kain, J. (2005). Teachers, schools, and academic achievement. Econometrica 73(2), 417-458.

Rock, M. L., Gregg, M., Thead, B. K., Acker, S. E., Gable, R. A., \& Zigmond, N. P. (2009). Can you hear me now? Evaluation of an online wireless technology to provide real-time feedback to special education teachers-in-training. Teacher Education and Special Education, 32(1), 64-82.

Ronfeldt, M., Farmer, S. O., McQueen, K., \& Grissom, J. A. (2015). Teacher collaboration in instructional teams and student achievement. American Educational Research Journal, 52, 475-514. doi: http://dx.doi.org/10.3102/0002831215585562dropbox

Ronfeldt, M., Loeb, S., \& Wyckoff, J. (2013). How teacher turnover harms student achievement. American Educational Research Journal, 50, 4-36. doi: http://dx.doi.org/10.3102/0002831212463813

Ronfeldt, M., Schwartz, N., \& Jacob, B. A. (2014). Does preservice preparation matter?: Examining an old question in new ways. Teachers College Record, 116, 1-46.

Rosenberg, M. S., Boyer, K. L., Sindelar, P. T., \& Misra, S. (2007). Alternative route programs to certification in special education: What we know about program design, instructional delivery, and participant characteristics. Exceptional Children, 73, 224-241.

Rosenberg, M. S., \& Sindelar, P. T. (2005). The proliferation of alternative routes to certification in special education: A critical review of the literature. The Journal of Special Education, 39, 117-127.

Ruble, L., \& McGrew, J. H. (2013). Teacher and child predictors of achieving IEP goals of children with autism. Journal of Autism and Developmental Disorders, 43, 2748-2763. doi: 10.1007/s10803-013-1884-x

Russ, S., Chiang, B., Rylance, B. J., \& Bongers, J. (2001). Caseload in special education: An integration of research findings. Exceptional Children, 67, 161-172. 
School and Staffing Survey (n.d.). SASS teacher questionnaire. Retrieved January 27, 2017 from http://nces.ed.gov/surveys/sass/questionnaire.asp.

Scruggs, T. E., Mastropieri, M. A., \& McDuffie, K. A. (2007). Co-teaching in inclusive classrooms: A metasynthesis of qualitative research. Exceptional Children, 73, 392-416.

Sindelar, P. T., Daunic, A., \& Rennells, M. S. (2004). Comparisons of traditionally and alternatively trained teachers. Exceptionality, 12(4), 209-223.

Sindelar, P. T., Heretick, J., Hirsch, E. Rorrer, A., \& Dawson, S. A. (2010). What district administrators need to know about state induction policy. The Journal of Special Education Leadership, 23(1), 5-13.

Sindelar, P. T., Shearer, D. K., Yendol-Hoppey, D., \& Liebert, T. W. (2006). The sustainability of inclusive school reform. Exceptional Children, 72(3), 317-331.

Singh, K., \& Billingsley, B. (1996). Intent to stay in teaching: Teachers of students with emotional disorders versus other special educators. Remedial and Special Education, 17(1), 37-47.

Skiba, R. J., Simmons, A. B., Ritter, S., Ruasch, M. K., Cuadrado, J., \& Chung, C. (2008). Achieving equity in special education: History, status, and current challenges. Exceptional Children, 74, 264-288.

Smith, S. J., \& Israel, M. (2010). E-mentoring: Solutions for teacher induction. The Journal of Special Education Leadership, 23(1), 30-40.

Smith, T. M., \& Ingersoll, R. M. (2004). What are the effects of induction and mentoring on beginning teacher turnover? American Educational Research Journal, 41(3), 681-714.

Steinbrecher, T. D., Fix, R., Mahal, S. A., Serna, L. A., \& McKeown, D. (2015). All you need is patience and flexibility: Administrators' perspectives on special educator knowledge and skills. Journal of Special Education Leadership, 28, 89-102.

Steinbrecher, T. D., Selig, J. P., Cosbey, J., \& Thorstensen, B. I. (2014). Evaluating special educator effectiveness: Addressing issues inherent to value-added modeling. Exceptional Children, 80, 323-336. doi: http://dx.doi.org/10.1177/0014402914522425

Sun, M. R., Loeb, S., \& Grissom, J. A. (March, 2016). Building teacher teams: Evidence of positive spillovers from more effective colleagues. Presentation at Association for Education Finance and Policy, Denver, CO.

Sun, M. R., Mutcheson, B., \& Kim, J. (2015). Teachers' use of evaluation for instructional improvement and school supports for this use. In J. A. Grissom \& P. Youngs (Eds.), Making the most of multiple measures: The impacts and challenges of implementing rigorous teacher evaluation systems (pp. 102-115). New York, NY: Teachers College Press.

Taylor, E. S., \& Tyler, J. H. (2012). The effect of evaluation on teacher performance. American Economic Review, 102, 3628-3651. doi: http://dx.doi.org/10.1257/aer.102.7.3628

Tyler, N., Yzquierdo, Z., Lopez-Reyna, N., \& Flippin, S. S. (2004). Cultural and linguistic diversity and the special education workforce: A critical overview. The Journal of Special Education, 38(1), 22-38.

Vannest, K. J. \& Hagan-Burke, S. (2010). Teacher time use in special education. Remedial and Special Education, 31, 125-142.

Vannest, K. J., Soares, D. A., Harrison, J. R., Brown, L., \& Parker, R. I. (2010). Changing teacher time. Preventing School Failure, 54, 86-98.

Walsh, K. (2001). Teacher certification reconsidered: Stumbling for quality. Baltimore, MD: The Abell Foundation. Retrieved February 5, 2017 from www.abell.og/publications/detail.asp?ID=59

Wanzek, J., \& Vaughn, S. (2007). Research-based implications from extensive early reading interventions. School Psychology Review, $36,541-561$.

Wanzek, J., Vaughn, S., Scammacca, N. K., Metz, K., Murray, C. S., Roberts, G., \& Danielson, L. (2013). Extensive reading interventions for students with reading difficulties after grade 3. Review of Educational Research, 83, 163-195.

Wasburn-Moses, L. (2010). Rethinking mentoring: Comparing policy and practice in special and general education. Education Policy Analysis Archives, 18, 1-25. doi: http://dx.doi.org/10.14507/epaa. v18n32.2010

Whitaker, S. D. (2000). Mentoring beginning special education teachers and the relationship to attrition. Exceptional Children, 66(4), 546-566.

Yoon, K. S., Duncan, T., Lee, S. W., Scarloss, B., \& Shapley, K. (2007). Reviewing the evidence on how teacher professional development affects student achievement (Issues \& Answers Report, REL $2007-$ No. 033). Washington, DC: U.S. Department of Education, Regional Educational Laboratory Southwest.

Youngs, P., Holdgreve-Resendez, R. T., \& Qian, H. (2011). The role of instructional program coherence in beginning elementary teachers' induction experiences. Elementary School Journal, 111, 455-476.

Youngs, P., Jones, N., \& Low, M. (2011). How beginning special and general education elementary teachers negotiate role expectations and access to professional resources. Teachers College Record, 113, $1506-1540$. 